\title{
Motivation, Satisfaction, and Risks of Operational Forces and Helpers Regarding the 2021 and 2013 Flood Operations in Germany
}

\begin{abstract}
Alexander Fekete
Institute of Rescue Engineering and Civil Protection, TH Köln-University of Applied Sciences, Betzdorfer Str. 2, 50679 Cologne, Germany; alexander.fekete@th-koeln.de

Abstract: Pluvial floods claimed more than 180 lives in Germany in July 2021, when a large and slow-moving storm system affected Germany and many neighbouring countries. The death tolls and damages were the highest since 1962 in Germany, and soon after, the crisis management was under public critique. This study has undertaken an online survey to understand crisis management better and identify lessons to learn. It has received a positive interest among operational relief forces and other helpers $(n=2264)$. The findings reveal an overall satisfaction with the operation in general as well as personal lessons learned. It also reveals shortcomings in many areas, ranging from information distribution, coordination, parallel ongoing COVID-19 pandemic, infrastructure resilience, and other factors. Just as well, areas for improvement of the crisis management system are suggested by the respondents. Cooperation and support by the affected population are perceived as positive. This helps to inform other areas of research that are necessary, such as studies on the perception by the affected people. The gaps in assessments of operational forces and some methodological constraints are discussed to advance future follow-up studies.
\end{abstract}

check for updates

Citation: Fekete, A. Motivation, Satisfaction, and Risks of Operational Forces and Helpers Regarding the 2021 and 2013 Flood Operations in Germany. Sustainability 2021, 13, 12587. https://doi.org/10.3390/ su132212587

Academic Editor: Michalis Diakakis

Received: 27 September 2021

Accepted: 12 November 2021

Published: 15 November 2021

Publisher's Note: MDPI stays neutral with regard to jurisdictional claims in published maps and institutional affiliations.

Copyright: (C) 2021 by the author. Licensee MDPI, Basel, Switzerland. This article is an open access article distributed under the terms and conditions of the Creative Commons Attribution (CC BY) license (https:// creativecommons.org/licenses/by/ $4.0 /)$.
Keywords: disaster management; emergency management; civil protection; flood Germany; needs assessment; loss and damage; volunteers; voluntary helpers; response

\section{Introduction}

The floods along riverine areas triggered by heavy rains in Europe resulted in amounts of death tolls and damages [1] not experienced in Germany in recent times since 1962. While riverine floods are rather common, and smaller pluvial floods have occurred in recent years more frequently, pluvial flood damages in this range were uncommon. But especially, the high death toll in an industrialised country that had not seen such high numbers and damages has been perceived as a surprise and shock [2]. Similar to other flood disasters elsewhere, the public debate soon started on questions of responsibility and guilt [3]. Crisis management came under critique from the media and the public [4,5].

Crisis management is used as an umbrella term in this article for related areas of disaster management, disaster response, or emergency management. In the context of German civil protection, crisis management is used for the phase of the disaster unfolding, while risk management is used for the phase of preparedness [6].

There have been many lessons-learned studies worldwide and in Germany after major flood events in 1993, 1995, 1997, 2002, 2006, and 2013 [7-11]. The topic of voluntary helpers is an international research topic regarding motivation and composition concerning age and values [12]. It became a topic of research in Germany, especially after the floods in 2013 [13,14]. However, the perspective of needs and motivations of official emergency personnel has hardly been addressed by empirical studies in Germany so far. Many studies exist on risks and disasters worldwide, but since this article is about a survey in Germany, it mainly focuses on German research.

Research on floods in Germany address hazard as well as impact, vulnerability, and resilience aspects. Forensic disaster assessments capture the flood triggers and key damages [15]. Research on floods about motivation and perception considers cross-sectional 
aspects, and some studies begin comparisons between different flood events [16]. Lessonslearned studies recurrently address shortcomings in risk management, coordination, and communication, for instance, for the significant flood events of 2002, 2013, and $2021[7,8,17]$.

People affected are analysed regarding their preparedness, household damages [17,18], perception towards flood risk and capacities [19,20], or recovery [21]. There is increasing research about a shift towards governance and a greater role for citizens in flood risk management and flood resilience [22-24], especially within the area of risk perception and social vulnerability [24] or community resilience [25,26]. This is also an emerging topic in semi-quantitative studies and modelling [27]. Psychological aspects about perceptions of risks are addressed by German researchers $[20,28]$ as well as motivational aspects $[29,30]$, but these need more investigations together with operational and disaster risk reduction aspects to form a more comprehensive view on risk-informed decision making [31]. An emerging topic in research in Germany is the integration of spontaneous or volunteer helpers into flood risk management $[32,33]$. There is an interest in using digital platforms to enable such integration [13] better. There are few studies about the operational organisations or people involved in them, but many on the overall flood risk governance approach $[34,35]$ exist. This study addresses the operational forces and helpers as a stakeholder group concerning their perceptions of problems and capacities. Similar approaches have focused mainly on affected people, with similar survey approaches and sample sizes [16].

Germany has been hit by flood events recurringly, and the events from 2013 and 2021 were the major events in the past decade regarding flood extent and damage. The 2013 flood was a riverine flood triggered by rainfall between 30 May and 3 June 2013 and has affected areas in 12 out of 16 of the German federal states as well as in other neighbouring countries, too. Precipitation sums reached over $200 \mathrm{~mm}$. Fourteen casualties were reported, and damages reached 8 billion $€[36]$.

The 2021 flood was triggered by heavy rainfall from 12-19 July 2021, with a peak between 13-15 July (up to 150-200 mm over three days) [37]. This storm system, "Bernd", affected areas in the west and some areas in the north, south, and east of Germany and neighbouring countries. With over 180 casualties [38], 40,000 people were affected by damages [39], another 165,000 were without electricity and mobile phone connection, and damages between 7 to 15 billion $€$ are estimated [40,41].

Since crisis management is at the forefront of acting upon disasters, it is a key stakeholder group and should be investigated more. A similar study we conducted in 2013 after major river floods affected Germany revealed a major need for more research on this stakeholder group and their motivations. A high number of the first responders and helpers responded to a survey on satisfaction with the operation $(n=3377)$. The responses revealed important insights into overall satisfaction, communication, and coordination aspects and lessons to learn [42]. It became apparent that studies on asking first responders and other roles in crisis management on their insights and opinions are still lacking, especially across organisations. To better understand the efficiency of crisis management in the floods in 2021 , it is important to analyse the insights of the stakeholder group of those who actively worked in crisis management at that time. This includes both professional emergency personnel and other official emergency personnel that conduct honorary work and voluntary helpers. In Germany, the majority are honorary official emergency helpers (over 1.7 million people) that continue to receive payment during operations [40]. Therefore, another survey has been carried out to include a wide range of this group from all layers of roles and organisations. The survey ran for three weeks, from 1 September to 21 September 2021 (with $n=2264$ ). To coordinate ongoing surveys and data collections in Germany, we initiated a data-sharing platform and discussion forum with the disaster preparedness committee (www.dkkv.org, accessed on 12 November 2021) [43]. In an online workshop organised by DKKV on 20 October 2021, 45 researchers and practitioners exchanged demands for further investigations of this flood event. Since there is a recognised paucity of longitudinal studies [44], this data-sharing platform can help to prepare such studies. This 
also addresses a demand within risk perception and behaviour studies recently recognised at the European level [45]. The article has the main purpose of informing the audience about the empirical data and findings from the survey. In addition, the relevance of more research on this stakeholder group and some methodological constraints are discussed.

This article includes sections on (i) methodology of the online survey, (ii) the main results of the 2021 survey in Germany, and (iii) a comparison with questions in a 2013 survey after a riverine flood in Germany. In the following section, (iv) further aspects of the stakeholder groups and constraints in methodology are discussed.

\section{Materials and Methods}

Immediately during and after the floods on 14 and $15 \mathrm{July}$, bilateral communication with operational emergency personnel, disaster experts, and students started triggering ideas on which areas within disaster management would warrant further investigation. Some of those involved in the ongoing response and recovery activities expressed an interest in hosting a joint lecture and discussion workshop, which was then co-organised by crisis management helpers and students at the Technical University in Cologne and took place on 4 August 2021. The intention was knowledge exchange and sharing experiences. The 74 participants were active in different professional and voluntary relief organisations; some were voluntary helpers, and some were affected themselves. In a co-creational process, the participants in different organisations expressed negative and positive experiences with the flood operations in 2021 that informed the survey content. The suggestions of topics to analyse and the minutes of the discussions are the basis for the development of the survey.

The hypotheses generated from this discussion guided the development of a questionnaire. Many questions were integrated from the 2013 survey and questionnaire, which had seen a similar development at the Technical University in Cologne [42]. With the focus group of persons involved actively in the flood 2021 operations and a pre-test group, the survey questions that are still relevant for 2021 were selected and adjusted where necessary. Additional question items were added based on the discussions in 2021, especially around the needs in infrastructure dependency, information and coordination processes, and others. Potential mental well-being and ethical issues in asking people soon after a disaster event have also been discussed with experts and the focus groups. Care was taken to avoid traumatic questions, frame them neutrally, and ensure anonymity and voluntariness in the participation were provided and communicated. Online surveying was selected for the same reasons as in 2013 to cover a wide range of roles, organisations and persons, and to enable open and wide participation while keeping participation anonymous and openly accessible. This is because it is a highly sensitive topic in an ongoing public discussion and since there are restrictions by the organisations for information sharing. It is understandable given the many lawsuits filed after the disaster [46], but there is also a traditional reservedness in openly expressing critique and self-critique across organisations. Known advantages of online surveys further include independence from local availability of respondents (Häder 2014), minimising effects of societal coercion and acceptability (Taddicken 2009), and time and cost savings (Kirch 2000). Known disadvantages include technical accessibility (Häder 2014). Age-group-related lower responses of the elderly also are a typical factor of online surveys [47].

The development team of the survey consisted of the author and persons involved in the operations or with the topic. Two sets of pre-tests were run: one (repeatedly) within the development team and one with external persons involved with the operations or the topic. The external pre-tester team comprised 60 people, including 20 outside of Germany. This is due to the survey also addressing neighbouring countries that also were affected by the flood. However, as for consistency, this article only covers the German areas affected. Another article will contain the international results.

The distribution started on 1 September 2021 to have a consistent time phase immediately after August and July, which were the most intense months for the response 
and recovery (Figure 1). The author distributed the survey online over different expert networks, research projects, and personal contacts to experts or helpers in the field and on various social media platforms connected to such experts (Twitter, LinkedIn). In addition, colleagues and students helped forward it to other experts or helpers directly. They posted it on social media platforms used by helpers in the floods (Facebook, WhatsApp, Instagram groups, etc.). Participation was voluntary, and participants could openly access it and distribute it further. Since recovery and repair missions continued in September, this survey is designed as a preliminary survey. Other running surveys were monitored; one had one overlapping question and ran until 6 September. Other surveys started later, and it takes some more months until the whole situation and recovery can be analysed holistically. A reminder addressing different additional networks was sent out on 7 September, which is reflected by the second surge of responses (Figure 1).

\section{Methodological approach of survey design}

a) Demand on exchange by first responders and students $\rightarrow>$ online meeting

b) Exchange and group discussion -> insights and hypotheses for further investigations

c) Development of an online questionnaire; a) continuation of 2013 survey and b) adding new relevant questions

d) Co-development and two rounds of pre-test; a) within the group b) with international experts

e) Distribution online; 1-21 September 2021

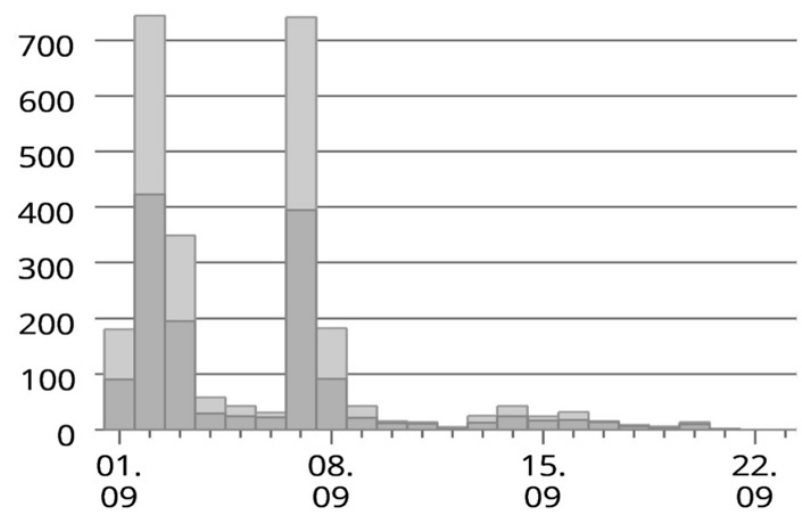

Survey responses per day

Figure 1. Study design and development of responses.

Known online survey constraints [47-49] have been observed; the survey tool used (SoSciSurvey) is open access, enables the filtering of double entries, can be used on different computer platforms and mobile, and can be translated into different languages. Mobile device usability is important for operational relief teams as well as anonymity. Therefore, we excluded questions on organisation name and location in terms of federal state. This is due to the specific organisation of relief organisations. Even at the district level, some organisations only have one person in a certain role or position, and demands for guaranteeing anonymity had been expressed before. The survey also avoids conducting comparisons of opinions or performances between organisations or the federal states since this is a sensitive topic. While one known constraint of online surveys is not tracking numbers of respondents clearly according to local contexts, we avoided some of this to guarantee anonymity. Still, a spatial relation to the affected areas is kept by a question. The high number of respondents who completed the survey in 2013 was due to this approach of spatial anonymity, as we learned by individual feedback.

The period of the survey from 1 September to 21 September 2021 did not see major other extreme events that changed the public mood. It must be mentioned that many additional hazard events happened at that time in Europe and worldwide, such as wildfires and pluvial floods. German national elections were on the 26 September, and the time before has seen public political debates about the flood and crisis management. The survey was closed before the election week to keep consistency.

The questionnaire is semi-structured and based on the hypotheses that were developed according to the literature on crisis and disaster management, risk perception, mental health, motivational, and stakeholder satisfaction studies [50-54]. The questionnaire is also based on the focus group discussions and developments in teams as described above. The questionnaire consists of closed and open-ended questions to capture direct generic 
comparability and open opinions and expressions. Twenty questions on motivational aspects and 11 questions on the context of the persons are included. These 31 questions include 24 closed questions and 7 open-ended questions. From the 2013 survey, 9 contentrelated closed questions were repeated to enable comparison, and more open-ended questions were added to go more in-depth. The survey contains one filter question at the beginning, which helps to separate those questions only applicable to those people who helped on-site, remotely, or who were voluntary helpers.

A time span of $10 \mathrm{~min}$ to fill in the questionnaire was targeted to suit the needs of operational forces, and the pre-tests revealed a mean of 8 min within the external and internal pre-test groups. The survey distribution documented the initial networks, social media platforms, and individual persons that were addressed by the authors. The survey questions were published so they can be compared to the findings in this article [55].

\section{Results}

From 1 September to 21 September 2021, 5986 clicks on the questionnaire were registered (which indicates a general high interest), and 2571 questionnaires were completed. After cleaning missing values and excluding non-completed questionnaires, a sample size of 2264 was analysed further using Excel and SPSS. From the 31 questions, the main results were selected, and not all questions or combinations of items can be covered here. The seven open-ended questions received entries from 159 to 911 respondents, summing up to around 37,400 words of additional text, or 94 pages.

\subsection{Background of the Respondents}

The majority had never been involved in a flood operation of this dimension before (54\%), but $32 \%$ had already participated in several such flood operations. The numbers are quite similar to the 2013 study ( $52 \%$ and $28 \%$, respectively).

Most respondents lived near the affected areas, within a $50-\mathrm{km}$ range (34\%) or within the same federal state (45\%), and 19\% live more than $50 \mathrm{~km}$ away. In 2013, 44\% lived in another federal state and more than $50 \mathrm{~km}$ away. Around $8 \%$ had been affected by the floods themselves in 2021.

The majority of respondents are male $(80.6 \%)$ and $18.6 \%$ female. Few persons were older than 60 years $(1.8 \%)$, and younger age groups were quite evenly represented, with a tendency towards 35 years and younger (Figure 2). Age profiles were almost similar in 2013, when gender distribution was $90 \%$ male and $10 \%$ female.

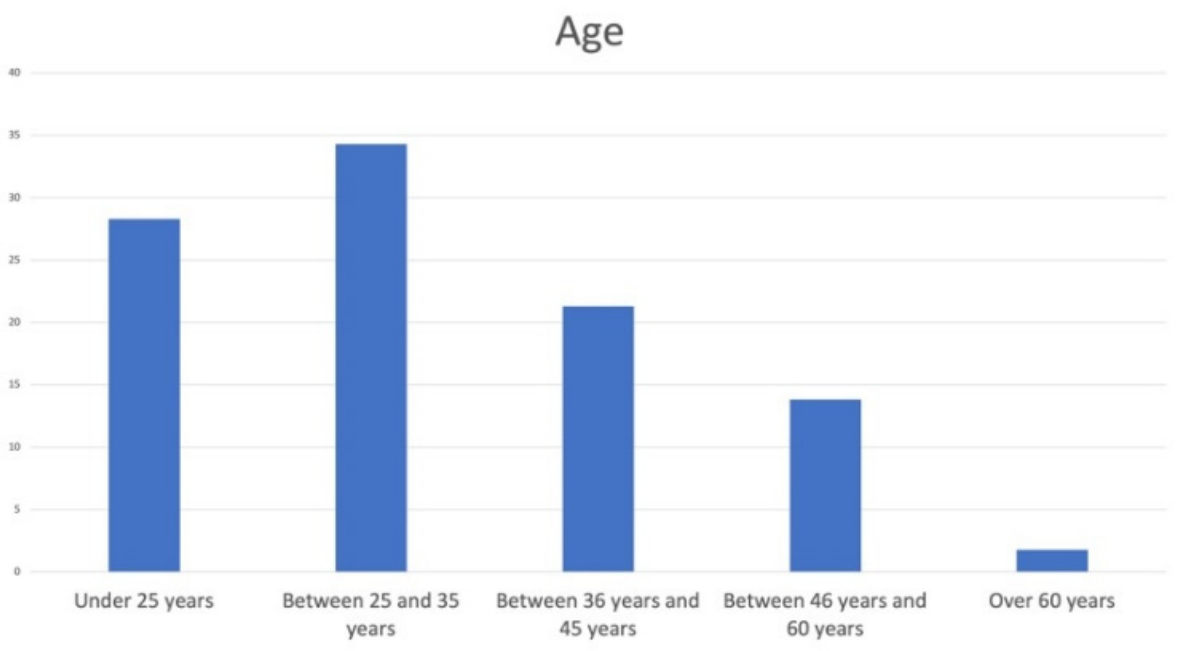

Figure 2. Age groups of respondents 2021 in \% $(n=1823)$.

The involvement in the operations varied between $8 \mathrm{~h}$ to more than four weeks (Figure 3). Many were deployed over one or two weeks in 2021 (23.7\%); in 2013, the average duration was one week. 


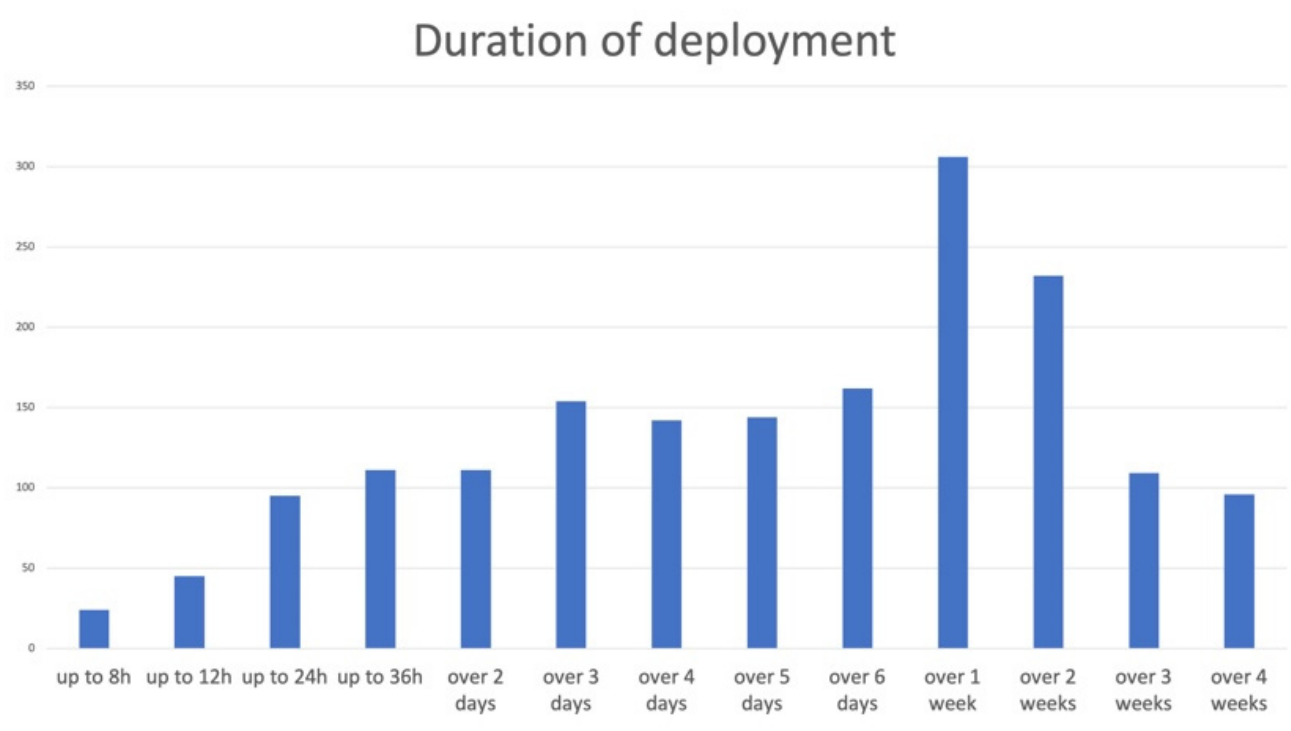

Figure 3. Duration of the operation deployment $(n=1766)$.

Regarding the role during the 2021 flood operation, the majority had no leadership function $(48 \%)$, and some were volunteer responders (11\%). From those with leadership, all ranks participated in almost equal numbers. Activations of specialist services were highest for technical assistance (44\%). Leadership qualification levels were distributed quite evenly amongst all ranks, and $29 \%$ had no formal qualification. A total of $75 \%$ participated within an honorary appointment (German: Ehrenamt), including organised volunteer organisations and probably many non-organised or spontaneous volunteers. Another $8 \%$ participated in a professional role, and this ratio to the honorary appointed quite well reflects the German crisis management, which mainly rests within organised volunteer organisations' hands. Based on the suggestion of the focus group discussions, the survey also asked those who participated in both roles, professional and honorary appointments, and this number is at $14 \%$. It indicates a high motivation of those who want to help, even doubly in both their professional job and honorary posts.

The main motivations of the respondents to participate in the flood operations, as captured by a specific additional question on it, were "saving people" $(72 \%)$ or "serving society" (70\%) (Table 1). Additionally, "to fight a hazard" and "colleagues/team" were motivations for most respondents. Almost half of the respondents selected "to do the job". Some of the hypotheses discussed in the pre-test group discussions before, such as "getting reputation/recognition" or "seeing/experiencing a hazard", were not selected as often. However, "helping from outside" was selected more often and may point towards the involvement of helper types beyond the traditional first responders.

Table 1. The main motivations of the respondents to participate in the flood operations $(2021, n=1744)$.

\begin{tabular}{ccc}
\hline Main Motivation & Frequency & Percentage \\
\hline Saving people & 1253 & 72 \\
Serving society & 1225 & 70 \\
To fight a hazard & 1027 & 59 \\
Your colleagues/team & 997 & 57 \\
To do the job & 825 & 47 \\
Not going on-site/helping from outside & 316 & 18 \\
Testing your own skills & 283 & 16 \\
Getting reputation/recognition & 136 & 6 \\
Seeing/experiencing a hazard & 111 & 4 \\
Other aspects & 72 & 1 \\
Not specified & 14 & 4 \\
\hline
\end{tabular}


Another aspect related to motivation to engage in a mission in some respects are worries when called to a response operation (Table 2). The majority expressed worries when the operation is about children (57\%). The second highest concern then was "aggressive communities" (42\%). For around one-third, it made no difference $(28 \%)$.

It is interesting to see that a worry about what could be termed persons at risk or vulnerable people is quite high, about $83 \%$ when combining worries about children and the elderly. It is quite remarkable that in a country like Germany, $42 \%$ are worried about aggressive or hostile communities.

Table 2. The worries when called to a response operation $(2021, n=1744)$.

\begin{tabular}{ccc}
\hline Worried, When & Frequency & Percentage \\
\hline It is about children & 996 & 57 \\
It is an aggressive community & 726 & 42 \\
It is not important to me/makes no difference & 486 & 28 \\
It is about elderly people & 284 & 16 \\
No worries & 153 & 9 \\
Other worries & 141 & 6 \\
It is a poor community & 101 & 6 \\
It is a high-rise building & 99 & 3 \\
Not specified & 58 & 2 \\
It is in an urban environment & 31 & 1 \\
It is a rural environment & 25 & 1 \\
It is a wealthy community & 17 & 6
\end{tabular}

3.2. The Main Results of the 2021 Survey in Germany and Comparison to 2013

\subsubsection{Involvement Type of the Helpers}

Based on the increasing numbers of involved voluntary helpers, we assumed it is important to include this stakeholder group into this questionnaire, too, even when it is mainly directed at operational and organised volunteer groups. One hypothesis was that this group, also sometimes called "unorganised volunteers", may be interested in this survey and express opinions different from the organised and professional helpers.

Regarding the involvement type, the majority of respondents (around 84.3\%) were on the site of the operation themselves. A total of $5 \%$ were on pre-alert or stand-by but not on-site; a similar number were involved administratively or organisationally (Table 3). Another 2.5\% were not involved, and around 2.8\% had other forms of participation. These two last groups received a sub-set of questions and will be analysed separately later on.

Table 3. Question 1. How were you involved in the 2021 flood operation?

\begin{tabular}{ccc}
\hline & Frequency & Percentage \\
\hline I was on-site in the area of operation. & 1909 & 84.3 \\
I was on pre-alert or standby but not on-site. & 113 & 5 \\
I was involved administratively or organisationally (not on-site). & 122 & 5.4 \\
I was not involved * & 57 & 2.5 \\
Other forms of participation * & 63 & 2.8 \\
Total & 2264 & 100 \\
\hline
\end{tabular}

* Filter question.

As an interpretation, this reveals the high number of respondents having hands-on experience and that quite a large number were helping remotely in different roles. This underlines our hypothesis that it is increasingly important to capture not only organised and professional types of involvement but also voluntary helpers, especially differentiating people helping on-site, with many also helping with remote work. Still, a separate survey designed specifically for voluntary helpers is necessary, which is also expressed in some of the open replies in later questions of this survey. 


\subsubsection{Personal Satisfaction with the Overall Flood Operation}

Based on the expressions of dissatisfaction and critique on the crisis management process in the focus group discussions as well as by individual replies, the hypothesis was that there could be a high ratio of dissatisfaction within the wider community.

Personal satisfaction with the overall flood operation was very positive for around $2.9 \%$ and positive for around $38.4 \%$. A total of $24.3 \%$ were neither satisfied nor dissatisfied, and a similar number was dissatisfied (Table 4, Figure 4). Around 7.1\% were very dissatisfied. Comparing the results of 2021 with 2013, satisfaction overall was much higher in 2013 than in 2021. In 2021, only about 3\% responded "very satisfied", while in 2013 , it was $62 \%$.

Table 4. Question 2. How satisfied are you personally with the overall flood operation?

\begin{tabular}{ccccc}
\hline & Frequency & Percentage & Accumulated \% & 2013 in \% \\
\hline Very satisfied & 66 & 2.9 & 2.9 & 62 \\
Satisfied & 870 & 38.4 & 41.4 & 13 \\
Neither & 550 & 24.3 & 65.8 & 13 \\
Dissatisfied & 557 & 24.6 & 90.4 & 8 \\
Very dissatisfied & 161 & 7.1 & 97.6 & 2 \\
No rating & 55 & 2.4 & 100 & 2 \\
Total & 2259 & 99.8 & & - \\
Missing & 5 & 0.2 & & 100 \\
Total & 2264 & 100 & & - \\
\hline
\end{tabular}

\section{Satisfaction with the flood operations 2013 and 2021}

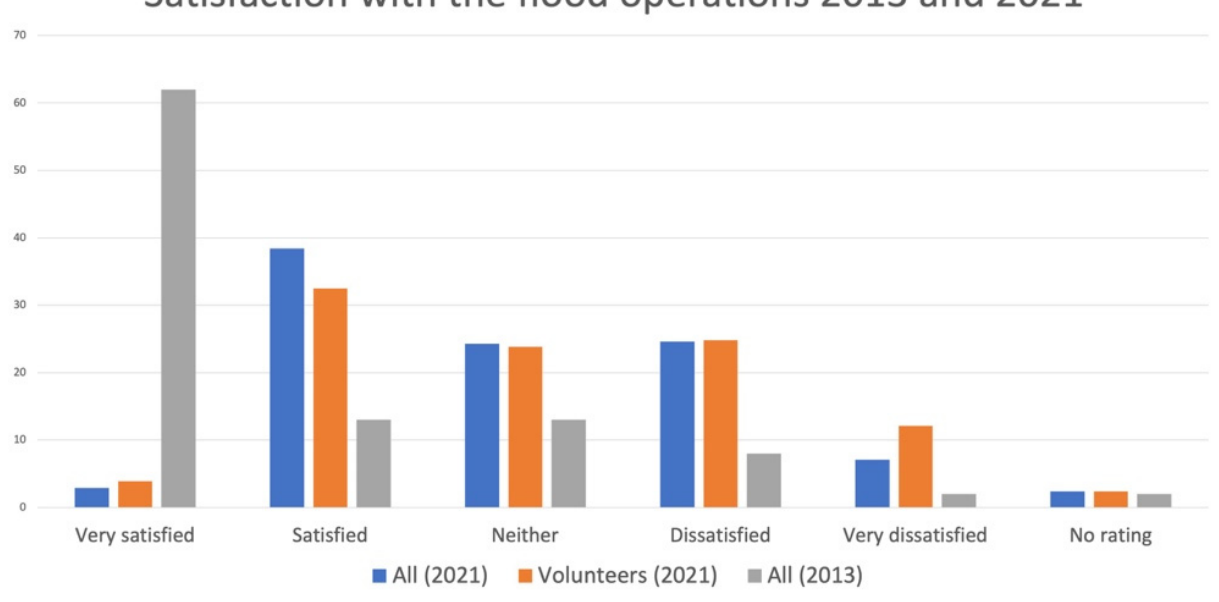

Figure 4. Satisfaction with the flood operation.

The data analysis in this study always contains all respondents except where explicitly indicated in the figures or tables (such as Figure 4). Interpreting the results, it is not an even distribution in 2021, with a slight preference for positive overall satisfaction. However, dissatisfaction is quite prominent, too, indicating the need for further investigation. Comparing replies from all respondents with the group of volunteers, the results are quite similar. There is a slight increase in the group of those very dissatisfied amongst the volunteers, however. The comparison with 2013 shows a great change in the group of respondents very satisfied with the operations. The differences to 2013 can be attributed to more gaps in information and communication, coordination, and other aspects in 2021, which the following questions and open replies in the surveys reveal.

The results partly fit our original hypothesis that there is some frustration with many aspects of crisis management from within those operational in the crisis management. However, overall, the picture is more positive since the majority expressed satisfaction with the operations. To understand whether this can result in a lower willingness to engage in further crisis management activities, further investigations are necessary, which are addressed by the follow-up question. 


\subsubsection{The Effect on the Personal Motivation to Help}

The hypothesis building upon the previous question was that a low motivation could result in a lower willingness to engage in crisis management. However, the results reveal that the motivation increased $(49.5 \%)$ for the majority, and for only about $10 \%$, it decreased (Table 5, Figure 5). Quite a high share expressed that it did not influence their motivation (38.6\%). Comparing the results of 2021 with 2013, the pattern is quite similar, but the number of those whose motivation decreased is higher in 2021.

Table 5. Question 3. Did the flood operation in 2021 have an effect on your personal motivation to help?

\begin{tabular}{cccc}
\hline & Frequency & Percentage & Percentage \\
$\mathbf{( 2 0 2 1 )}$ & $\mathbf{( 2 0 2 1 )}$ & (2013) \\
\hline Yes, my motivation has increased. & 1120 & 49.5 & 53 \\
No, the assignment had no influence on my motivation. & 874 & 38.6 & 42 \\
Yes, my motivation has decreased. & 229 & 10.1 & 5 \\
No answer & 41 & 1.8 & - \\
Total & 2264 & 100 & 100 \\
\hline
\end{tabular}

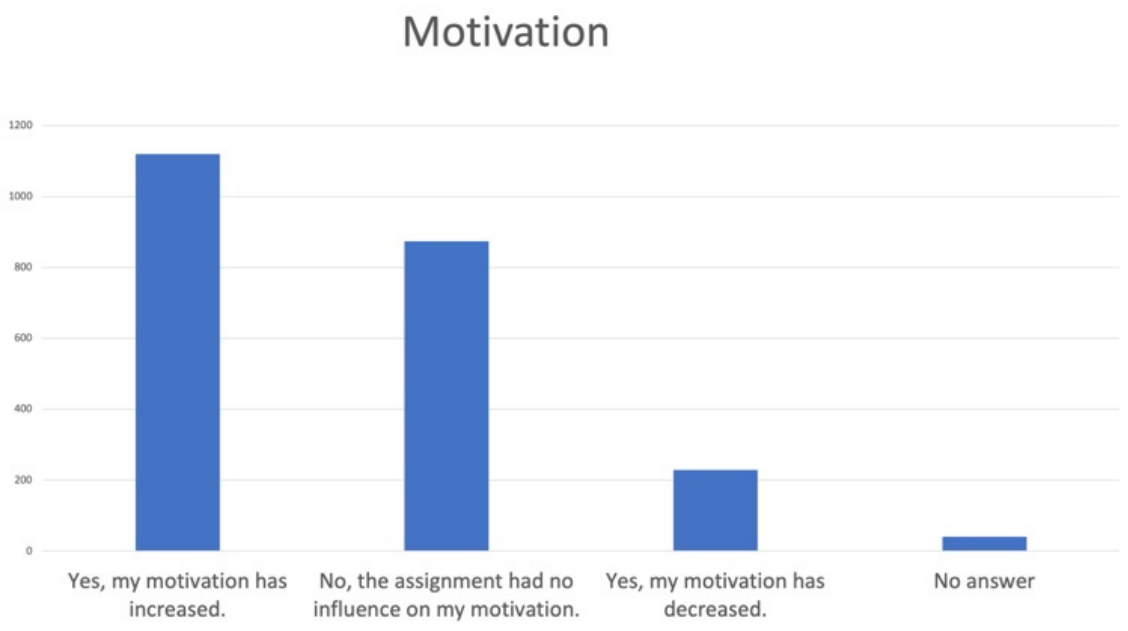

Figure 5. The effect on the personal motivation to help.

The results may be interpreted to display an overall positive picture of motivation as generally high, as shown in the previous question. This corresponds to the results in 2013 and to other studies on first responders or volunteers [12,14]. However, the relatively high number of people who saw no change could already point to some underlying issues or needs for further research as to whether these stakeholder groups actually would need more motivation. The following survey questions try to analyse additional motivational aspects that can help point out reasons for increasing or decreasing motivation in flood operations. However, since many of the respondents are already active in daily emergency management (see Section 3.2), a single event may not have such a strong impact on motivation. In comparison to the 2013 survey results, it is apparent that the decrease in overall satisfaction is also followed by a decrease in motivation. One finding to increase motivation to engage in flood operations from 2013 was to provide more after-care and express interest in the opinions and experiences of the helpers. The 2021 survey, therefore, continued to ask helpers about satisfaction and motivation and areas to improve future flood operations. However, academic surveys are limited, and the helper organisations themselves must conduct after-care and feedback discussions. Moreover, some of the open responses reveal that, indeed, such feedback and re-cap conversations were conducted. However, the results also reveal that many aspects of coordination and communication have not improved in the past years. This can probably not be solved by the individual organisations, but inter-organisational coordination must be improved. 


\subsubsection{The Preparation for the Flood Operation}

Based on discussions with operational teams in 2013 and 2021, the hypothesis was formed that preparation is important to consider regarding the satisfaction with the operations. To investigate this and to go deeper into the questions about motivation before, the following question addresses a personal rating of the overall preparation. Based on several discussions with persons involved, we kept the question general to capture motivation perceptions for all stakeholder groups, including voluntary helpers. Therefore, this question does not differentiate between technical training, education, or other aspects, which will be captured later in more detailed questions.

The results show that the majority in 2021 rate their preparation as good or very good (accumulated 51.5\%) and another quarter as satisfactory (Table 6, Figure 6). Poor ratings are given by $12 \%$ and very poor by $6 \%$. By comparison, in 2013, preparation was perceived as slightly better.

Table 6. Question 4. How would you personally rate your preparation for the flood operation (for example, through training and exercises)?

\begin{tabular}{cccc}
\hline & Frequency (2021) & Percentage (2021) & Percentage (2013) \\
\hline Very good & 359 & 15.9 & 22 \\
Good & 808 & 35.7 & 44 \\
Satisfactory & 552 & 24.4 & 23 \\
Poor & 274 & 12.1 & 6 \\
Very poor & 135 & 6 & 2 \\
No rating & 136 & 6 & 3 \\
Total & 2264 & 100 & 100 \\
\hline
\end{tabular}

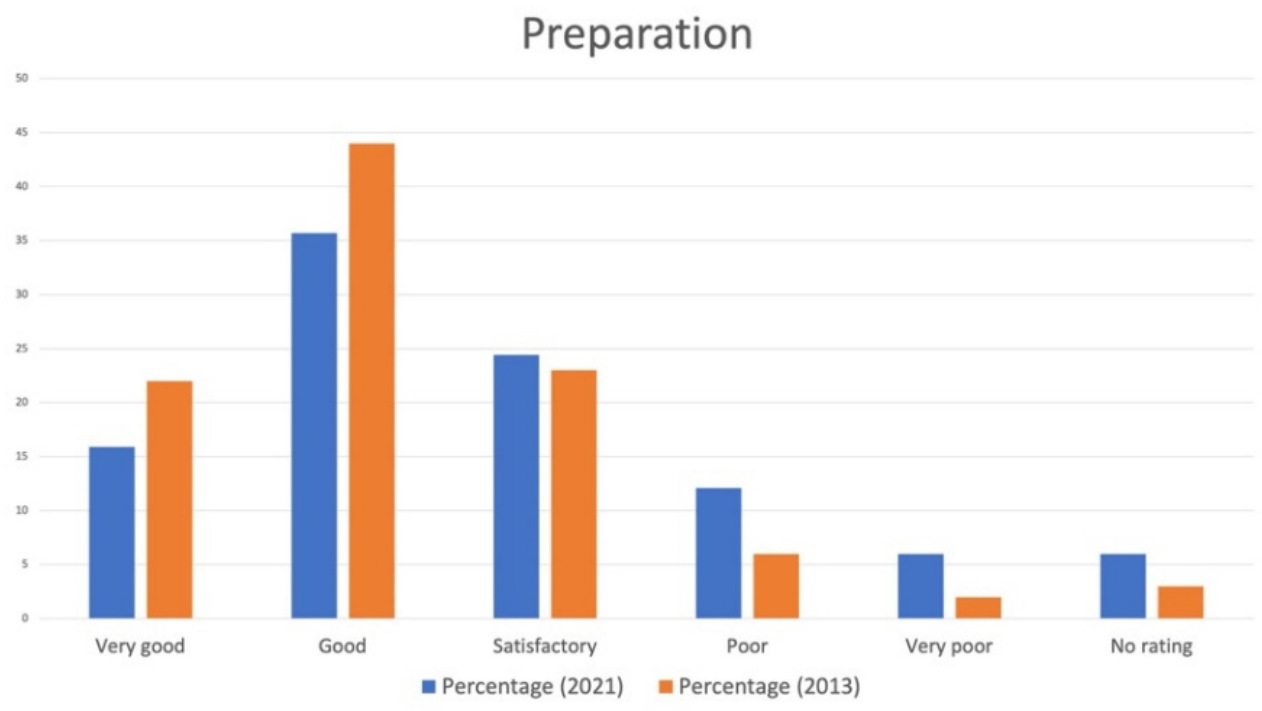

Figure 6. The preparation for the flood operation.

Overall, the respondents were positive about their preparation to cope with the flood operation. This seems to confirm the rather positive overall picture from the previous questions. However, the comparison with the 2013 survey data reveals an overall decrease in preparation satisfaction. In the open replies in 2021, a certain critique in the provision of information but also materials were expressed (see later sections).

\subsubsection{The Provision with Information before and during an Operation}

In line with preparation in general, one aspect identified in conversations with operational teams is the provision of information before and during an operation. Based on 
previous experience with missing information, the hypothesis was formed that helpers would be more satisfied when information is provided before and during the operations.

A mixed result of a mostly satisfactory impression on information provision and relatively high numbers of poor or very poor impressions becomes visible (Table 7, Figure 7). The results do not differ much between the phase of information provision before or during the operation in 2021. However, by comparison with 2013, satisfaction in 2021 is lower.

Table 7. Question 5. How did you personally feel about the provision of information about your deployment (a) before it started and (b) during the operation?

\begin{tabular}{|c|c|c|c|c|c|c|}
\hline & $\begin{array}{l}\text { Frequency (a) } \\
\text { before }(2021)\end{array}$ & $\begin{array}{l}\text { Percentage } \\
\text { (2021) }\end{array}$ & $\begin{array}{l}\text { Frequency (b) } \\
\text { during (2021) }\end{array}$ & $\begin{array}{l}\text { Percentage } \\
(2021)\end{array}$ & $\begin{array}{l}\text { Percentage (a) } \\
\text { before (2013) }\end{array}$ & $\begin{array}{l}\text { Percentage (b) } \\
\text { during (2013) }\end{array}$ \\
\hline Very good & 79 & 3.5 & 113 & 5 & 16 & 13 \\
\hline Good & 397 & 17.5 & 404 & 17.8 & 36 & 32 \\
\hline Satisfactory & 609 & 26.9 & 631 & 27.9 & 28 & 32 \\
\hline Poor & 525 & 23.2 & 527 & 23.3 & 13 & 16 \\
\hline Very poor & 376 & 16.6 & 333 & 14.7 & 7 & 6 \\
\hline No rating & 54 & 2.4 & 33 & 1.5 & 0.5 & 1 \\
\hline Total & 2040 & 90.1 & 2041 & 90.2 & - & - \\
\hline Missing & 224 & 9.9 & 223 & 9.8 & - & - \\
\hline Total & 2264 & 100 & 2264 & 100 & 100 & 100 \\
\hline
\end{tabular}

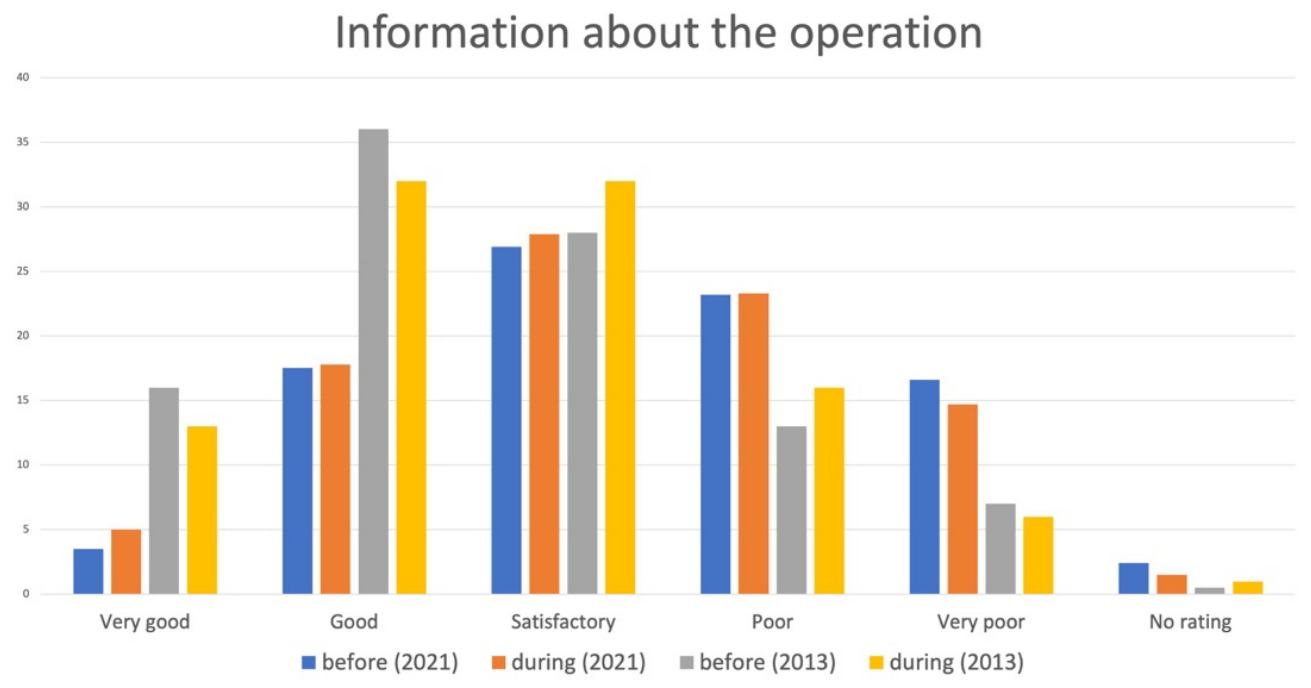

Figure 7. Information provision before and during the operations in 2021 and 2013.

The results indicate gaps in information provision in general. Contrary to the mostly positive picture of the previous questions, some gaps in information provision may contribute to expressions of dissatisfaction, too. This result fits the qualitative results in the previous focus group discussions and media reports, where information and communication issues were quite predominant. More detailed insights into types of communication are captured by additional questions introduced in the 2021 survey (see Section 3.2.10 and following questions). The comparison with 2013 consistently indicates a decrease in satisfaction in regard to information provision, too. In 2021, coordination and information gaps dominated the public discussions much more than in 2013, which could also impact the perceptions of the respondents. On the other hand, specific topics, such as issues with the digital radio, are mentioned in the open replies and could help explain a lower satisfaction in 2021.

\subsubsection{The General Cooperation among the Helpers}

In previous conversations and experiences with other operations, the hypothesis was generated that cooperation between helpers is a key component of a successful operation. 
Human factors, such as personal trust and interpersonal relations, play an important role, especially in professional and organised emergency management. Therefore, it is of interest to investigate how the overall picture was in the flood operations.

The results reveal an overall very positive picture: about $92 \%$ combined agree to the cooperation being perceived as satisfactory at least and good or even very good $(40.3 \%)$. Only $3.8 \%$ expressed poor and only $1.1 \%$ very poor cooperation (Table 8 , Figure 8 ). Cooperation was perceived slightly better in 2013.

Table 8. Question 6. How do you personally rate the general cooperation among the helpers during the flood operation?

\begin{tabular}{cccc}
\hline & Frequency (2021) & Percentage (2021) & Percentage (2013) \\
\hline Very good & 823 & 36.4 & 48 \\
Good & 774 & 34.2 & 40 \\
Satisfactory & 290 & 12.8 & 9 \\
Poor & 86 & 3.8 & 1 \\
Very poor & 26 & 1.1 & 0.2 \\
No rating & 43 & 1.9 & 2 \\
Total & 2042 & 90.2 & - \\
Missing & 222 & 9.8 & - \\
Total & 2264 & 100 & 100 \\
\hline
\end{tabular}

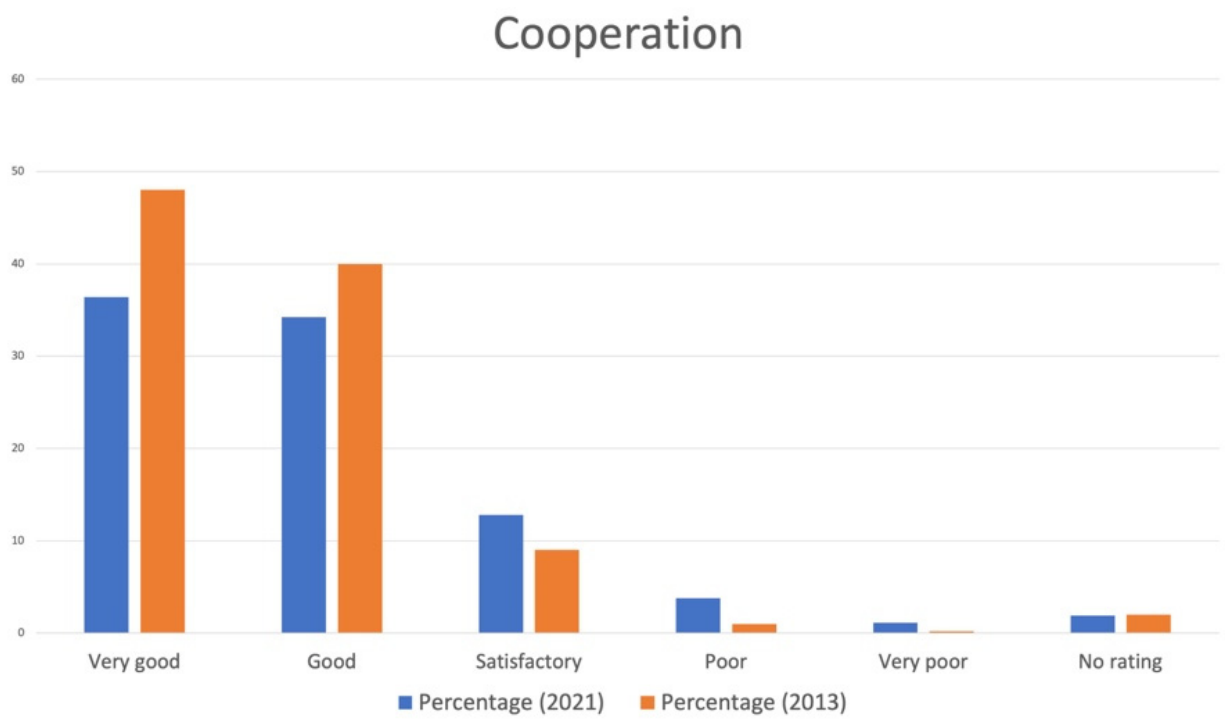

Figure 8. The cooperation among the helpers.

The results indicate a high level of satisfaction with cooperation, which could also be a key component to understanding the overall satisfaction or its positive aspects. This assumption is underlined by the high number of voluntary expressions to positive experiences between helpers and the people affected in the open replies (see Section 3.2.13). It is interesting that satisfaction about cooperation also decreased in comparison to 2013 even though this aspect may not be directly related to information provision but rather to coordination.

\subsubsection{The Behaviour of Immediate Superiors}

Many discussions revealed the importance of cooperation and leadership in developing the surveys in 2013 already and in 2021. While it is quite a sensitive question, leadership is aligned with cooperation and hence behaviours of the leadership. Therefore, the hypothesis was formed that the behaviour of the superiors is a factor to consider when investigating satisfaction about the flood operation. 
The results show that the behaviour of the superiors in 2021 was perceived overall as quite positive and at least satisfactory by an accumulated $80 \%$ of the respondents. A total of $7.2 \%$ of the respondents express poor and $4.4 \%$ very poor estimations (Table 9, Figure 9). The results cannot directly be compared to the 2013 data since the new selection field "did not have a supervisor" was added in 2021 to better suit voluntary helpers. However, the numbers would suggest that the perception was slightly more positive in 2013.

Table 9. Question 7. How did you personally feel about the behaviour of your immediate superiors during the flood operation?

\begin{tabular}{ccccc}
\hline & $\begin{array}{c}\text { Frequency } \\
(\mathbf{2 0 2 1 )}\end{array}$ & $\begin{array}{c}\text { All in \% } \\
\mathbf{( 2 0 2 1 )}\end{array}$ & $\begin{array}{c}\text { Highest Level } \\
\text { in \% (2021) }\end{array}$ & $\begin{array}{c}\text { All in \% } \\
\mathbf{( 2 0 1 3 )}\end{array}$ \\
\hline Very good & 488 & 21.6 & 17.3 & 36 \\
Good & 728 & 32.2 & 30.8 & 41 \\
Satisfactory & 354 & 15.6 & 25.2 & 13 \\
Poor & 164 & 7.2 & 12.1 & 5 \\
Very poor & 100 & 4.4 & 7.5 & 2 \\
No rating & 40 & 1.8 & 2.3 & - \\
Did not have a supervisor & 74 & 3.3 & 2.3 & \\
Total & 1948 & 86 & & \\
Missing & 316 & 14 & & \\
Total & 2264 & 100 & & \\
\hline
\end{tabular}

\section{Behaviour of superiors}

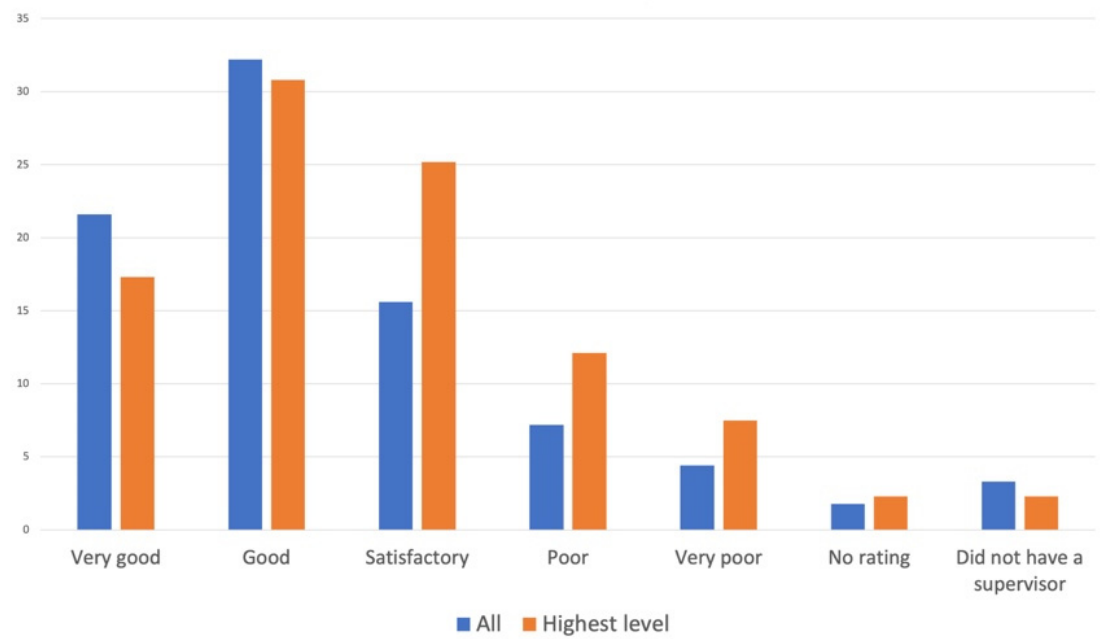

Figure 9. The behaviour of immediate superiors, as perceived by all $(n=2264)$ and by those who achieved the highest level of advanced training $(n=209)$.

The results indicate some areas for improvements, but overall, it could be interpreted that the behaviour of the superiors was not the main problem in the flood operations when regarded for all respondents. A preliminary investigation of the open-answer replies also revealed no indication. However, it is quite interesting to see a diverging pattern within the subgroup of those who had received the highest levels (degrees) of advanced training (Figure 9). They reported poor and very poor experiences more often. A comparison with the 2013 data reveals a slightly better impression in 2021 in the two most positive categories. This could point towards a higher ratio of behavioural issues of superiors in the 2013 operations.

\subsubsection{Post-Event Follow-Up}

In line with the previous hypothesis about preparation, information, and cooperation, many discussions revealed a gap in after-event feedback opportunities and exchange in 
2013 and 2021. The hypothesis to be investigated is whether the perceptions about followups are a factor to consider when investigating satisfaction about the flood operation.

The results show that quite high numbers expressed positive experiences: more than $53 \%$ were at least satisfactory, $4.5 \%$ were poor, and $2.7 \%$ were very poor. Another $24.6 \%$ expressed that there was no follow-up (Table 10, Figure 10).

Table 10. Question 8. How did you personally feel about the follow-up (if there was any) after the flood operation?

\begin{tabular}{cccc}
\hline & Frequency (2021) & Percentage (2021) & Accumulated \% \\
\hline Very good & 282 & 12.5 & 14.5 \\
Good & 505 & 22.3 & 40.4 \\
Satisfactory & 248 & 11 & 53.2 \\
Poor & 102 & 4.5 & 58.4 \\
Very poor & 62 & 2.7 & 61.6 \\
No rating & 191 & 8.4 & 71.4 \\
There was none & 556 & 24.6 & 100 \\
Total & 1946 & 86 & \\
Missing & 318 & 14 & \\
Total & 2264 & 100 & \\
\hline
\end{tabular}

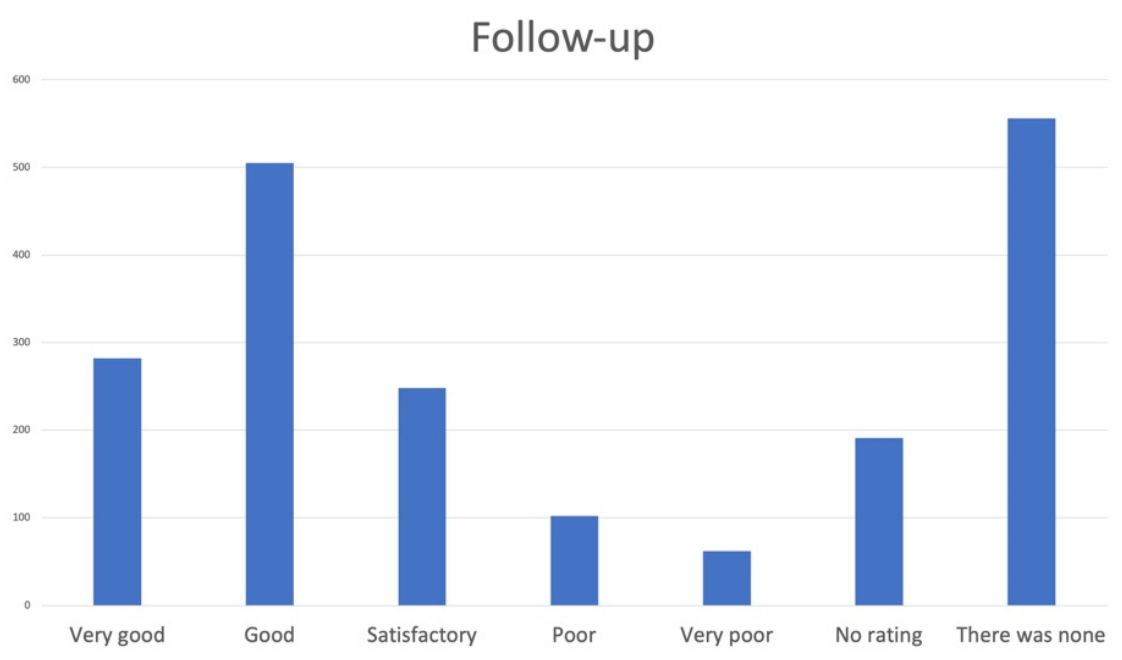

Figure 10. Perception of follow-ups.

The results are preliminary since the survey started on 1 September, and this would not leave much time for follow-ups yet. Therefore, it cannot be compared to the 2013 results. However, the high number of positive responses in 2021 indicates that follow-up talks have happened already. The high number of no follow-up activities would have to be analysed further with studies on later periods after the flood operations.

\subsubsection{The Psychological Strain during the Flood Operation}

In line with the discussions in the development of the survey and informed by the literature on motivational theory and related psychological aspects, the relevance of psychological factors was of interest for this study. The hypothesis posited that psychological strains influence flood operations and thereby contribute to satisfaction.

The results show that psychological strains in 2021 were perceived by $7.3 \%$ as very high, $28.7 \%$ as high, $24.1 \%$ as balanced, $13.3 \%$ as low, and $9.3 \%$ as very low (Table 11 , Figure 11). In 2013, the psychological strain was slightly higher. 
Table 11. Question 9. How did you personally feel about the psychological strain during the flood operation?

\begin{tabular}{cccccc}
\hline & Frequency & All (2021) & $\begin{array}{c}\text { Volunteers } \\
\mathbf{( 2 0 2 1 )}\end{array}$ & $\begin{array}{c}\text { Highest } \\
\text { Training (2021) }\end{array}$ & All (2013) \\
\hline Very high & 165 & 7.3 & 11.7 & 8.9 & 17 \\
High & 650 & 28.7 & 44.2 & 31.8 & 35 \\
Balanced & 546 & 24.1 & 22.8 & 24.8 & 21 \\
Low & 301 & 13.3 & 9.7 & 19.2 & 18 \\
Very low & 210 & 9.3 & 7.8 & 10.3 & 5 \\
No rating & 77 & 3.4 & 3.4 & 2.8 & 4 \\
Total & 1949 & 86.1 & & & \\
Missing & 315 & 13.9 & & & \\
Total & 2264 & 100 & &
\end{tabular}

\section{Psychological strain}

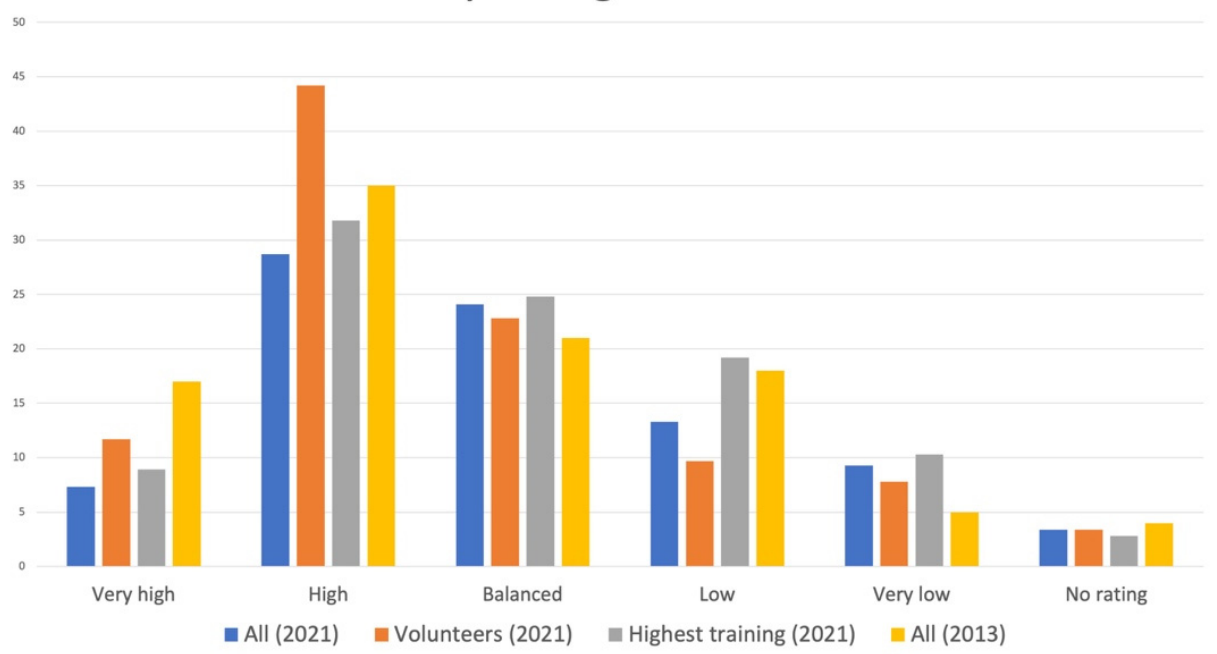

Figure 11. The psychological strain of all in the operations, of volunteers $(n=205)$, and of those with the highest level of advanced training $(n=209)$.

The findings indicate a tendency to rather high psychological strains in all groups. However, it is also interesting to see many responses that expressed low or very low strains or problems. Whether this is due to the general professional environments and activities that many respondents are involved in either day-to-day or by previous similar flood operation experiences must be further investigated. A first comparison with the group of volunteers shows that they expressed a higher psychological strain, while those with the highest forms of training expressed lower ranges.

One step towards this is a further investigation of problem areas suggested by the people involved in the discussions and development of this survey. The following question reveals many problem areas and shows how psychological problems are regarded compared to other problem fields. In comparison to 2013, psychological strains appear higher in 2021. The open replies do not reveal indications about the reasons, so further studies are necessary to shed light on this. The pandemic could have created underlying conditions of psychological unease, potentially rendering the ability to take on new disasters more difficult. The number of casualties, the ratio of affected respondents, the destruction of infrastructure, and a parallel ongoing pandemic were captured by additional questions in the section below, which may all contribute to higher stress aspects.

\subsubsection{Problems Identified}

The following question items were collected from suggestions and discussions within focus groups after the 2021 flood events and the pre-test group. The idea was to capture a 
wide range of problem fields and trigger more additional problem reports to be entered in an open question field.

The ten problem fields with the highest numbers of responses (Table 12) starts with "missing information" (51\%) and contains other aspects related to information, such as "misinformation from official sources" $(32 \%)$ and "misinformation from the media" (27\%). Fields related to information furthermore include "digital radio" $(40 \%)$ and "alerting/mission preparation/mission recording" (38\%). The other five problems fields include "command and coordination in the field" (50\%), "underload/long breaks/waiting" $(38 \%)$, "replacement, long shifts" (32\%), "assignment of tasks (to one personally)" (31\%), and "uncooperative population/community" $(28 \%)$. The five problem fields with the lowest frequency of responses are "protective equipment COVID-19", "no problems at all", "preparation of own organisation", "sickness (not COVID-19)", and "infected with COVID-19 during deployment period". Many more problem fields are contained in the results but are too many to be covered here in detail; they can be found in Annex A.

Table 12. Question 10. Did you experience any problems in these subject areas? (2021, multiple replies, $n=1903)$.

\begin{tabular}{ccc}
\hline Problems & Frequency & Percentage \\
\hline Missing information & 980 & 51 \\
Command and coordination in the field & 956 & 50 \\
Digital radio & 761 & 40 \\
Alerting/mission preparation/mission recording & 725 & 38 \\
Underload/long breaks/waiting & 718 & 38 \\
Misinformation from official sources & 611 & 32 \\
Replacement, long shifts & 601 & 32 \\
Assignment of tasks (to one personally) & 593 & 31 \\
Uncooperative population/community & 529 & 28 \\
Misinformation from the media & 507 & 27 \\
\hline
\end{tabular}

The high ratio of problem fields and responses to issues related to missing information or misinformation points out relevant fields for further investigation. They correlate to the focus group discussions before and media reports after the flood in 2021. It is interesting to note that the results here provide additional information about information provision before and during the flood in Question 5. While the results in Question 5 can be interpreted as a mixed result, with positive and negative experiences with information provision, Question 10 underlines the need for further investigation of the problems associated with it. In this line, the high numbers of problem responses to command and coordination in the field also point out additional demands for more in-depth investigations. Since the behaviour of superiors (Question 7) or the general cooperation (Question 6) do not seem to represent the problem with overall satisfaction, there seems to be quite some room for discussion or improvement. Moreover, the other problem fields in the ten most highly mentioned problem fields also point towards personal issues with the operations, such as length of shifts, assignment of tasks, etc. A problem in public debate and media after the floods but especially amongst operational forces was the digital radio. "Uncooperative population/community" needs further investigation, and it is interesting to compare this with an open answer question in the questionnaire that asked about what they would have liked the population to do or how the population could have supported or facilitated the operations. The results show that it seems to be less correlated with a lack of thankfulness, cooperation, or helpfulness of the people affected (see Section 3.2.13 below) but maybe rather with coordination with the authorities in the communities. It is interesting to note that "psychological stress" was mentioned by 17\% (Appendix A) but is not in the highest number of problem fields. Quite interesting is also that COVID-19-related problems did not seem to be that high by comparison with the other problem fields. 


\subsubsection{Infrastructure Failure}

The topic of critical infrastructure has gained quite some importance in German civil protection and crisis management contexts in the past years. Since in the immediate aftermath of the floods in 2021, damages of roads, bridges, railway, electricity, water and sewage, IT, and communications were key issues in reports and public media, an additional question was added on infrastructure failure. While almost all infrastructure was damaged in many areas, it was of interest to find out which were perceived to have the greatest impact on the capabilities of the crisis management to deal with the floods.

The results show that traffic route failures affected $52 \%$ of the respondents in their operations, followed by communication links (39\%), digital radio $(38 \%)$, electricity $(30 \%)$, and water $(27 \%)$. No impairment was reported by $23 \%$ (Table 13$)$.

Table 13. Question 11. Has an infrastructure failure affected you during operations? (2021, multiple replies, $n=1852$ ).

\begin{tabular}{ccc}
\hline Infrastructure & Frequency & Percentage \\
\hline Wastewater & 333 & 18 \\
Water & 507 & 27 \\
Communication links (civil, private) & 716 & 39 \\
Digital radio & 709 & 38 \\
Electricity & 550 & 30 \\
Traffic routes & 968 & 52 \\
Catering & 314 & 17 \\
Other (which?) & 30 & 2 \\
No impairment & 421 & 23 \\
\hline
\end{tabular}

The results indicate important areas for improving the capabilities of operational organisations in terms of autonomous supply with infrastructure services. Destroyed roads can only partly be compensated by alternative routing over gravel roads in the affected areas of the Ahr valley, for example. This is due to a lack of redundant roads in the quite steep valley there. The open replies reveal further indications of shortages in equipment, such as trucks or cars able to drive through water depths of more than $30-50 \mathrm{~cm}$. The failure recorded in the answers here on communication lines and digital radio corresponds to the responses in the previous questions. However, these failures also are connected to electricity failure since mobile communication is dependent on it. Therefore, the relatively high number of no impairments reported may be interpreted as a good signal. Only $2 \%$ mentioned other infrastructure failures, which may indicate that the suggested question items developed after the discussions with first responders cover the most relevant. Still, it cannot be ruled out that a more in-depth investigation could bring up more problems associated with infrastructure.

\subsubsection{Situations at Risk}

Discussions with first responders and emergency teams revealed increasing violence and hostility against them in the past years. This occurred in the recent past [56] but also in the flood operation in 2021, when responders were hindered in accessing areas by misinformation, theft, or even garbage thrown at them [57]. It was, therefore, interesting to ask the helpers about which risks they would perceive themselves. The underlying hypothesis here was that the flood itself, COVID-19, and violence could be relevant risks.

The results show that the majority ( $47 \%$ ) did not perceive situations of risk (Table 14). From the risks mentioned, rest periods that were not respected $(18 \%)$ and misinformation were highest $(17 \%)$, followed closely by the floods $(15 \%)$. 
Table 14. Question 12. Were there any situations in which you felt yourself to be at risk? (2021, multiple replies, $n=1852$ ).

\begin{tabular}{ccc}
\hline Risks & Frequency & Percentage \\
\hline No & 845 & 46 \\
Rest periods not respected & 336 & 18 \\
Misinformation & 311 & 17 \\
Floods & 272 & 15 \\
COVID-19 & 166 & 9 \\
Violations of operational principles & 164 & 9 \\
Violence against emergency services & 140 & 8 \\
Other & 116 & 6 \\
Not specified & 137 & 7 \\
\hline
\end{tabular}

\subsubsection{Positive Experiences}

To test the opposite as well, positive experiences were investigated. This was based on the findings in 2013 but also on the discussion with operative forces during the flood operations in 2021 and on media reports on solidarity [58].

As analysed by search term frequencies, the results to this open question reveal that thankfulness, cohesion with the population affected and team members, as well as the related term cooperation were mentioned most often. Only nine respondents expressed no positive experiences (Table 15). Since this assessment is based on open-reply questions, the replies consist of both emotional perceptions and perceptions about missing materials or resources.

Table 15. Question 13. Were there any aspects of your assignment that you found particularly positive? (2021, Open question, $n=911)$.

\begin{tabular}{ccc}
\hline & Frequency & Percentage \\
\hline Thankfulness & 219 & 24 \\
Cohesion & 182 & 20 \\
Cooperation & 148 & 16 \\
Helpfulness & 90 & 10 \\
Camaraderie & 49 & 5 \\
Catering & 36 & 4 \\
Team & 30 & 3 \\
Solidarity & 22 & 2 \\
No & 9 & 1 \\
\hline
\end{tabular}

The results support a balanced view of the respondents on the operations. While there is a substantial critique on details and many expressed frustrations about an uncooperative population/community in Question 10, they received a great deal of gratefulness and support. The sample size is almost half of the number of responses in the preselected question items in Question 10. Therefore, it cannot be ruled out that those expressing their frustrations in Question 10 did not enter open texts in this Question 13. However, from seven open-ended questions, this was the one with the highest number of entries.

\subsubsection{Areas of Improvement}

After questions on problems, risks, and positive experiences, suggestions of improvements were asked. The improvement areas were again selected in the development phase of the survey and were based on the discussions and consistent with previous questions. In addition, an open-ended question field was also offered here.

The results reveal that improvements were regarded as most necessary in "command and control" (58\%), followed by "coordination of emergency forces" (55\%). More than 50\% also expressed that "equipment of the organisation", "exchange, feedback between organisations", "demand planning, pre-planning", "exchange across federal states' borders", 
and "information of the population about activities and limits of the activities of emergency forces" are necessary (Table 16). The three least selected items were "post-employment care", "digital platforms", and "psychological and social support services".

Table 16. Question 14. In which areas do you think improvements are necessary so that volunteers return more satisfied from future missions? (2021, multiple replies, $n=1911)$.

\begin{tabular}{ccc}
\hline & Frequency & Percentage \\
\hline Command and control & 1108 & 58 \\
Coordination of emergency forces & 1055 & 55 \\
Equipment of the organisation & 1021 & 53 \\
Exchange, feedback between organisations & 1016 & 53 \\
Demand planning, pre-planning & 1014 & 53 \\
Exchange across federal states' borders & 993 & 52 \\
the activities of the emergency forces & 592 & 52 \\
Information lime population, about the activities and limits of & 45 \\
Preparation/planning for longer missions & 868 & 41 \\
Communication & 792 & 36 \\
Exchange, feedback within an organisation & 687 & 35 \\
Rocumenting and sharing knowledge and experience & 668 & 32 \\
Risk maps, situation pictures & 508 & 30 \\
Persons who transfer knowledge between organisations & 461 & 25 \\
Visual material of dangerous situations digital/virtual & 461 & 24 \\
Visual material of dangerous situations in real life & 447 & 23 \\
Training of emergency forces in self-protection & 440 & 23 \\
Cross-border exchange with neighbouring countries in the EU & 417 & 22 \\
Post-employment care & 406 & 21 \\
Digital exchange platforms & 354 & 19
\end{tabular}

The results are interesting, as the aspects selected most often all point towards an improvement of the coordination and resources or processes of the crisis management. This underlines previous results from the other questions. As it is a preselected list, it should not be overinterpreted, but it is certainly also of interest to note that psychological support is selected by much fewer respondents. Some other findings are also counter-intuitive or contrary to opinions expressed in the focus group discussions and to findings of individual responses in the adjacent open-ended question to this question. For example, digital maps were found lacking, but the results here do not support this. It can be assumed that the usability of digital maps and risk maps also is not yet much known or common, as we know from other projects in Germany.

\section{Discussion}

The discussion will focus on two aspects: the range of stakeholders reached and methodological constraints. This can help inform what additional analyses are helpful to achieve a more holistic picture of this significant flood event.

\subsection{Capturing Stakeholders in Crisis Management and Their Motivations}

The results of this survey fit well with the findings that came out from the focus groups discussions, field visits, and expert workshops conducted after the event. The target group of this survey is mainly professionals within emergency and disaster management, and the results reflect their opinions as captured by other methods, such as interviews. This stakeholder group exposes a balanced mentality of high motivation, being critical, and having high expectations on the operability of the administration and coordination within first responders. The survey reached about $11 \%$ of volunteers, which makes additional analyses necessary to better capture their experiences and views. However, this analysis also tried 
to highlight a few insights into their opinions, and in terms of being critical and having high expectations, they seem similar to the professionals. The debate and expression of frustrations of voluntary helpers and people affected have not been covered here, which is well documented within certain social media groups, such as Facebook groups in the affected regions. More surveys are being developed to capture these stakeholder groups as well. It will be also very useful to compare the results of this survey with other surveys that were running after the flood events. Care was taken not to duplicate surveys, but on the other hand, certain overlapping questions or additional questions can be very useful to compare results and capture a development within certain time phases after the disaster. To better align ongoing surveys and data collections and to reduce the stress on the people affected and the other stakeholder groups, we set up a website and network to unite other researchers with their ongoing investigations, together with a known and respected institution for disaster preparedness in Germany (www.dkkv.org, accessed on 12 November 2021). The response rate of 2264 completed questionnaires is lower than in 2013 (3377), but this can be due to the shorter run-time of three weeks instead of six and due to many other surveys in 2021 going on in parallel. It will be very interesting to compare the findings with other surveys, too.

\subsection{Methodological Constraints}

The findings presented in this paper include a rich data set, and this article has conducted only a preliminary analysis of it so far. Further comparisons of the results per stakeholder group, per age and gender groups, per level of training, etc., will be conducted as well as descriptive statistical tests. The 94 pages of open-reply text will need to be analysed in terms of what further details can be derived to explain the quantitative survey results. The survey has some shortcomings, such as the number of questions. These were kept short to accommodate the needs expressed by the target groups. Many of them were still on operation in the flood-affected areas or already back into daily emergency management. Therefore, the survey was designed and adjusted in the pre-tests to take no longer than $10 \mathrm{~min}$, which limited the number and depth of questions. A few crossquestions were included to check for consistency; for example, the ratio of volunteers was captured by one question to be $11.6 \%$ and in another to be $11.3 \%$. The constraints of an anonymous online survey include possible fraudulent use. However, the survey software allows for checking against automated robots, and a manual check of the data revealed no conspicuous duplications of the same entries. Another methodological constraint lies within the preselected question items in some questions. This was motivated by the discussions before the survey when the focus group discussions revealed these aspects to be relevant. The survey, therefore, tried to check whether these results from a rather open and qualitative method would also come out of a quantitative survey. Overall, the results all fit very well with the previously suggested research items. Still, even while open answers were possible, only a few additional categories could be added so far. The in-depth analysis of the open-answer texts may reveal more problems or suggestions for worries, positive experiences, and improvements than captured here. The time that passed between the onset of the impacts and operations in July to the start of the survey could have affected the respondents' views and feelings. In discussions with the focus groups and pre-testers, this was considered, and the time phase of the survey was agreed upon as a good distance to the event. Additionally, related ethical questions were considered, and it was taken care that the survey questions did not disturb the feelings of the respondents. Since emotional reactions could not be ruled out, the survey contained an option to stop or pause the survey at any time. In addition, open-reply fields or "no response" options also were included. As soon as other surveys are published that started earlier or later, comparisons can be made when certain specific questions asked can allow for this analysis. 


\subsection{Implications for Science and Practice}

Flood risk management at the international level has acknowledged a paradigm shift, analysing not only hazards but also focusing on impacts, vulnerabilities, and resilience. This paradigm shift has been addressed by German researchers [59], but the uptake of such concepts into the practice of flood risk management is still an ongoing challenge [60]. The United Nations call for risk-informed decision making [31], but the survey reveals that missing information was a major issue. Additional open replies of the survey reveal that specific risk-based information was missing, such as warnings or risk maps. The European Flood Directive has introduced compulsory risk management and risk mapping. However, expert workshops (13 September 2021 at DKKV with disaster experts) and focus group discussions (19 October 2021 at TH Köln with students and emergency personnel) revealed that the download figures were very low over the years before the flood happened in July 2021. It seems that a risk-informed society and crisis management in Germany need more data literacy concerning the usage of risk maps. Still, gaps remain, such as information being available but not being used by practitioners. One such information and communication gap that became apparent in the 2021 floods was the early warning. While information about the hazard existed and was shared by responsible organisations, it did not trickle down to every community and person (oral. com. at an expert meeting organised by DKKV on 20 October 2021). Some of the open-reply responses seem to confirm that risk maps were missing or not known, for example. It is not only missing information but also a missing uptake of information. Even more, the idea of the last mile or rather first mile [61], developed also with the help of German researchers in countries such as Indonesia [62-64], has not been addressed much in Germany yet. This is partly due to the German crisis and risk management being established top-down mostly. The bottom-up involvement of different stakeholder groups aside from the operational forces is a rather ad-hoc process, revealed in the 2021 floods once more. Help, especially in the recovery process with tens of thousands of volunteers, was organised by private persons themselves, such as transfer bus shuttles or donations [65]. This is not a new phenomenon, and social media has helped to gather such spontaneous volunteer groups [13]. Even some of the professional or honorary official helpers engaged as private persons, too, to circumvent waiting for the official detachments (oral. com. with the focus groups).

International studies also have analysed emergency volunteer helpers but rather concerning their motives to become engaged [12], recruitment [66], and retention [67], including work-life balance [68]. This is a big topic in Germany, too, to maintain a large number of honorary persons (German: Ehrenamt) [69-71]. The mental health of caregivers [72] or coping and trauma is another field of research covered quite well [73], but in Germany, there is less research on this [74] and the related field of human factors [75]. Satisfaction studies of professionals include medical doctors in relation to disaster relief and humanitarian assistance [76]. However, internationally and especially in Germany, there is a research gap on empirical, large-sample surveys on motivational and mental well-being aspects of the professional emergency helpers. At the European or international level, some studies exist but often only for single organisations, such as firefighters, or single topics, such as risk perception of hazards [70].

For practice, there are many implications for the advancement of operational crisis management as well as for better integration of preparedness and risk-informed decision making. This includes coordination and early warning, more transparency to what extent help from official organisations can be expected by the people in a disaster, and even more importantly, what help cannot be expected. Risk and crisis communication with the public must be improved from issuing information about a hazard to including advice on actions to be taken. More information flows from the people affected to the official, and communication between organisations and across borders must be improved, which the survey reveals. However, further investigations by in-depth interviews and commissions must also analyse the potential and limitations of the existing communication culture between the professional emergency organisations and between them and the public. This 
communication appears to be a key point explaining many of the dissatisfactions on coordination expressed by the respondents in this study. The professional and volunteer helpers seem to have a very high motive to engage and help and high correspondent demands on a perfectly working system. To address their motivational aspects can be a key recommendation to maintain the system built upon the readiness of helpers, most of them honorary or volunteer helpers.

\section{Conclusions}

The results from 2021 repeat the overall picture from 2013; while there is quite a great deal of dissatisfaction amongst professional and organised helpers on details on the operation, the overall satisfaction and motivation to provide help and be active in flood operations are high. The specific findings per survey question show a balanced picture of positive experiences and gaps, problems, and areas for improvement. The discussion shows that first responders and crisis managers are a special target group with high ambitions and that is surprisingly open to addressing failures in coordination and cooperation. As within focus group discussions before, this gives the impression of a target group that has a high motivation to help and engage and offers critique to improve the overall operability and capabilities of the whole crisis management system. This is quite interesting since such ambitions are directed at management even in a disaster, which is typically defined by overwhelming even the best preparations. The survey methodology also shows areas for further improvements, such as a more detailed analysis of the open-ended question sections and comparisons with other studies. Even more, it shows that other stakeholder groups must be analysed to better complement the picture on diverging views on crisis management as a system, its functionality, and how to improve it. In addition, though, topic areas for further research were identified, such as demands for more research on the social vulnerability of those in need of help, violence in communities, and fears of first responders. Moreover, infrastructure failures point out further needs for research on the self-autonomy of crisis management organisations. Self-autonomy, satisfaction, motivation, coordination, cooperation, and organisation contribute to making crisis management more resilient to cope with the next flood and to make such efforts more long-lasting, enduring, balanced, and hence sustainable as well.

Funding: This research received no external funding.

Institutional Review Board Statement: Ethical review and approval were obtained from the head of the TH Köln-University of Applied Sciences, since the ethical review board was not operationally established yet. Ethical questions were considered by the author by testing the survey also on ethical questions in two pretest rounds with 74 experts in the field of disaster risk management and related, national and international.

Informed Consent Statement: Informed consent was obtained from all subjects involved.

Data Availability Statement: The data supporting the reported results can be found on our website; riskncrisis.wordpress.com, accessed on 12 November 2021.

Acknowledgments: The author wishes to express respect and gratitude to those who helped in the flood operations 2021 for their service and for their help and stimulation to develop and carry out this survey and to everyone who participated in it and helped distribute it. The author also is grateful to Christian Baumgarten and Christian Bentler for providing the 2013 questionnaire and their readiness to support this survey as well as feedback. The author is grateful to Samuel Rufat, who helped design the survey to include other countries and perspectives. Gratitude is also expressed to the pre-test group for their inputs and readiness to improve this survey.

Conflicts of Interest: The author declares no conflict of interest. 


\section{Appendix A}

Table A1. Question 1. How were you involved in the 2021 flood operation?

\begin{tabular}{|c|c|c|}
\hline Problems & Frequency & Percentage \\
\hline Missing information & 980 & 51 \\
\hline Command and coordination in the field & 956 & 50 \\
\hline Digital radio & 761 & 40 \\
\hline Alerting/mission preparation/mission recording & 725 & 38 \\
\hline Underload/long breaks/waiting & 718 & 38 \\
\hline Misinformation from official sources & 611 & 32 \\
\hline Replacement, long shifts & 601 & 32 \\
\hline Assignment of tasks (to one personally) & 593 & 31 \\
\hline Uncooperative population/community & 529 & 28 \\
\hline Misinformation from the media & 507 & 27 \\
\hline Maps not available or up to date & 477 & 25 \\
\hline Was affected by the floods myself (or my family) & 468 & 25 \\
\hline Rest facilities & 424 & 22 \\
\hline Material and equipment for these situations (e.g., night operations) & 403 & 21 \\
\hline Self-inflicted injuries & 369 & 19 \\
\hline Hygiene & 356 & 19 \\
\hline Over-motivation of individual emergency personnel & 341 & 18 \\
\hline Compatibility with family/care (relatives, pets) & 340 & 18 \\
\hline Psychological stress & 315 & 17 \\
\hline Contamination spread & 287 & 15 \\
\hline Mission documentation/evaluation & 272 & 14 \\
\hline Protective equipment general & 267 & 14 \\
\hline Other problems & 249 & 13 \\
\hline Self-endangerment & 246 & 13 \\
\hline Overload & 242 & 13 \\
\hline Overwork/lack of training & 238 & 13 \\
\hline Lost tools & 210 & 11 \\
\hline Press appointments/visits by politicians & 201 & 11 \\
\hline Contamination of clothing (site hygiene) & 193 & 10 \\
\hline Compatibility with job & 156 & 8 \\
\hline Unprepared population/community & 128 & 7 \\
\hline Access roads blocked & 120 & 6 \\
\hline Protective equipment COVID-19 & 83 & 4 \\
\hline No problems at all & 50 & 3 \\
\hline Preparation of own organisation & 40 & 2 \\
\hline Sickness (not COVID-19) & 19 & 1 \\
\hline Infected with COVID-19 during deployment period & 5 & 0 \\
\hline
\end{tabular}

\section{References}

1. Schäfer, A.; Mühr, B.; Daniell, J.; Ehret, U.; Ehmele, F.; Küpfer, K.; Brand, J.; Wisotzky, C.; Skapski, J.; Rentz, L.; et al. Hochwasser Mitteleuropa, Juli 2021 (Deutschland). 21. Juli 2021-Bericht Nr. 1, Nordrhein-Westfalen E Rheinland-Pfalz"; Center for Disaster Management and Risk Reduction Technology: Eggenstein-Leopoldshafen, Germany, 2021; p. 31.

2. Cornwall, W. Europe's deadly floods leave scientists stunned. Science 2021, 373, 372-373. [CrossRef]

3. Mathiesen, K.; Von Der Burchard, H.; Gehrke, L. Over 100 Die in Germany, Belgium Floods despite Early Warnings. 2021. Available online: https: / / www.politico.eu/article/germany-floods-dozens-dead-despite-early-warnings/ (accessed on 4 September 2021).

4. Mannheim, F.; Schenk, N. Wann Hat wer Gewarnt?-Eine Rekonstruktion. 2021. Available online: https://www1.wdr.de/ nachrichten/landespolitik/chronologie-hochwasser-warnungen-100.html (accessed on 4 September 2021).

5. Völlnagel, I. Warum Kam die Warnung so Spät? 2021. Available online: https://www.tagesschau.de/inland/hochwasserwarnung-101.html (accessed on 4 September 2021).

6. BBK. BBK-Glossar. Ausgewählte Zentrale Begriffe des Bevölkerungsschutzes; Bundesamt für Bevölkerungsschutz und Katastrophenhilfe: Bonn, Germany, 2011.

7. DKKV. Lessons Learned. In Hochwasservorsorge in Deutschland. Lernen aus der Katastrophe 2002 im Elbegebiet; DKKV: Bonn, Germany, 2003; p. 151.

8. Thieken, A.H.; Kienzler, S.; Kreibich, H.; Kuhlicke, C.; Kunz, M.; Mühr, B.; Müller, M.; Otto, A.; Petrow, T.; Pisi, S. Review of the flood risk management system in Germany after the major flood in 2013. Ecol. Soc. 2016, 21, 51. [CrossRef] 
9. Kundzewicz, Z.W.; Szamalek, K.; Kowalczak, P. The great flood of 1997 in Poland. Hydrol. Sci. J. 1999, 44, 855-870. [CrossRef]

10. Felgentreff, C. Impact of the 1997 Odra flood on flood protection in Brandenburg (FRG): The Dyke broke, but the local people's trust in technical solutions remained unbroken. In Proceedings of the European Conference on Advances in Flood Research, Potsdam, Germany, 1-3 November 2000; pp. 614-626.

11. Fink, A.; Ulbrich, U.; Engel, H. Aspects of the January 1995 flood in Germany. Weather 1996, 51, 34-39. [CrossRef]

12. Francis, J.E.; Jones, M. Emergency service volunteers: A comparison of age, motives and values. Aust. J. Emerg. Manag. 2012, 27, 27-32.

13. Kaufhold, M.-A.; Reuter, C. The self-organization of digital volunteers across social media: The case of the 2013 European floods in Germany. J. Homel. Secur. Emerg. Manag. 2016, 13, 137-166. [CrossRef]

14. Fathi, R.; Thom, D.; Koch, S.; Ertl, T.; Fiedrich, F. VOST: A case study in voluntary digital participation for collaborative emergency management. Inf. Process. Manag. 2020, 57, 102174. [CrossRef]

15. Kunz, M.; Zschau, J.; Wenzel, F.; Khazai, B.; Kunz-Plapp, T.; Trieselmann, W. Forensic Disaster Analysis in Near-real Time. In Proceedings of the EGU General Assembly Conference Abstracts, Vienna, Austria, 27 April-2 May 2014.

16. Thieken, A.H.; Bessel, T.; Kienzler, S.; Kreibich, H.; Müller, M.; Pisi, S.; Schröter, K. The flood of June 2013 in Germany: How much do we know about its impacts. Nat. Hazards Earth Syst. Sci. 2016, 16, 1519-1540. [CrossRef]

17. DKKV. Flutkatastrophe Juli 2021 Vom Starkregen zur Katastrophe; DKKV: Bonn, Germany, 2021; p. 39.

18. Thieken, A.; Kreibich, H.; Müller, M.; Merz, B. Coping with floods: Preparedness, response and recovery of flood-affected residents in Germany in 2002. Hydrol. Sci. J. 2007, 52, 1016-1037. [CrossRef]

19. Kreibich, H.; Thieken, A.H.; Petrow, T.; Müller, M.; Merz, B. Flood loss reduction of private households due to building precautionary measures-Lessons learned from the Elbe flood in August 2002. Nat. Hazards Earth Syst. Sci. 2005, 5, 117-126. [CrossRef]

20. Kuhlicke, C.; Steinführer, A.; Begg, C.; Bianchizza, C.; Bründl, M.; Buchecker, M.; De Marchi, B.; Di Masso Tarditti, M.; Höppner, C.; Komac, B.; et al. Perspectives on social capacity building for natural hazards: Outlining an emerging field of research and practice in Europe. Environ. Sci. Policy 2011, 14, 804-814. [CrossRef]

21. Plapp, T.; Werner, U. Understanding risk perception from natural hazards: Examples from Germany. In RISK21-Coping with Risks due to Natural Hazards in the 21st Century; CRC Press: London, UK, 2006; pp. 111-118.

22. Bubeck, P.; Thieken, A.H. What helps people recover from floods? Insights from a survey among flood-affected residents in Germany. Reg. Environ. Chang. 2018, 18, 287-296. [CrossRef]

23. Depietri, Y.; Welle, T.; Renaud, F.G. Social vulnerability assessment of the Cologne urban area (Germany) to heat waves: Links to ecosystem services. Int. J. Disaster Risk Reduct. 2013, 6, 98-117. [CrossRef]

24. Kuhlicke, C.; Scolobig, A.; Tapsell, S.; Steinführer, A.; De Marchi, B. Contextualizing social vulnerability: Findings from case studies across Europe. Nat. Hazards 2011, 58, 789-810. [CrossRef]

25. Steinführer, A.; Kuhlicke, C. Social Vulnerability and the 2002 Flood; Country Report Germany (Mulde River): Leipzig, Germany, 2007.

26. Masson, T.; Bamberg, S.; Stricker, M.; Heidenreich, A. “We can help ourselves”: Does community resilience buffer against the negative impact of flooding on mental health? Nat. Hazards Earth Syst. Sci. 2019, 19, 2371-2384. [CrossRef]

27. Kruse, S.; Abeling, T.; Deeming, H.; Fordham, M.; Forrester, J.; Jülich, S.; Karanci, A.N.; Kuhlicke, C.; Pelling, M.; Pedoth, L. Conceptualizing community resilience to natural hazards-the emBRACE framework. Nat. Hazards Earth Syst. Sci. 2017, 17, 2321-2333. [CrossRef]

28. Evers, M.; Almoradie, A.; de Brito, M.M. Enhancing flood resilience through collaborative modelling and multi-criteria decision analysis (MCDA). In Urban Disaster Resilience and Security; Springer: Berlin/Heidelberg, Germany, 2018; pp. $221-236$.

29. Goersch, H.G. Problems of preparedness and its promotion in Germany. J. Emerg. Manag. 2014, 12, 449-456. [CrossRef] [PubMed]

30. Fathi, R.; Tonn, C.; Schulte, Y.; Spang, A.; Gründler, D.; Kletti, F.; Fiedrich, F.; Fekete, A.; Martini, S. Untersuchung der Motivationsfaktoren von Spontanhelfern. In Proceedings of the Preis des Posterwettbewerbs in 15. DKKV Forum Katastrophenvorsorge, Berlin, Germany, 3-4 November 2015.

31. Holwitt, P.; Strohschneider, S.; Zinke, R.; Kaiser, S.; Kranert, I.; Linke, A.; Mähler, M. A study of motivational aspects initiating volunteerism in disaster management in Germany. Int. J. Saf. Secur. Eng. 2017, 7, 294-302. [CrossRef]

32. United Nations. Sendai Framework for Disaster Risk Reduction 2015-2030; United Nations Office for Disaster Risk Reduction: Geneva, Switzerland, 2015.

33. Poser, K.; Dransch, D. Volunteered geographic information for disaster management with application to rapid flood damage estimation. Geomatica 2010, 64, 89-98.

34. Hälterlein, J.; Madsen, L.; Schuchardt, A.; Peperhove, R.; Gerhold, L. Integrating volunteers in emergency response: A strategy for increased resilience within German Civil Security Research. In Urban Disaster Resilience and Security; Springer: Berlin/Heidelberg, Germany, 2018; pp. 113-128.

35. Heintz, M.D.; Hagemeier-Klose, M.; Wagner, K. Towards a risk governance culture in flood policy-Findings from the implementation of the "floods directive" in Germany. Water 2012, 4, 135-156. [CrossRef]

36. Fleischhauer, M.; Greiving, S.; Flex, F.; Scheibel, M.; Stickler, T.; Sereinig, N.; Koboltschnig, G.; Malvati, P.; Vitale, V.; Grifoni, P. Improving the active involvement of stakeholders and the public in flood risk management-tools of an involvement strategy and case study results from Austria, Germany and Italy. Nat. Hazards Earth Syst. Sci. 2012, 12, 2785-2798. [CrossRef] 
37. DKKV (Hrsg., 2015) Das Hochwasser im Juni 2013. Bewährungsprobe für das Hochwasserrisikomanagement in Deutschland. DKKV-Schriftenreihe Nr. 53, Bonn, Germany. 2015. Available online: https://www.dkkv.org/fileadmin/user_upload/ Veroeffentlichungen/Publikationen/DKKV_53_Hochwasser_Juni_2013.pdf (accessed on 20 October 2021).

38. Junghänel, T.; Bissolli, P.; Daßler, J.; Fleckenstein, R.; Imbery, F.; Janssen, W.; Kaspar, F.; Lengfeld, K.; Leppelt, T.; Rauthe, M.; et al. Hydro-klimatologische Einordnung der Stark- und Dauerniederschläge in Teilen Deutschlands im Zusammenhang mit dem Tiefdruckgebiet "Bernd" vom 12. bis 19. Juli 2021; DWD: Offenbach, Germany, 2021; p. 16.

39. BPB. Jahrhunderthochwasser 2021 in Deutschland. 2021. Available online: https://www.bpb.de/politik/hintergrund-aktuell/33 7277 /jahrhunderthochwasser-2021-in-deutschland (accessed on 20 October 2021).

40. Zeit, D. Rund 40.000 Menschen im Ahrtal von Hochwasser-Folgen betroffen. 2021. Available online: https://www.zeit.de/ gesellschaft/2021-07/hochwasser-rheinland-pfalz-ahrweiler-folgen-ueberschwemmung? (accessed on 15 October 2021).

41. GDV. Ver si che rungs schä den durch Flut ka ta stro phe bei rund sie ben Mil li ar den Euro. 2021. Available online: https://www. gdv.de/de/medien/aktuell/versicherungsschaeden-durch-flutkatastrophe-bei-rund-sieben-milliarden-euro-69800 (accessed on 18 October 2021).

42. Baumgartner, C.; Bentler, C.; Fekete, A. Studying extreme events from the perspective of the disaster relief workers involved in 2013 floods in Germany. In Recovery after Extreme Events. Lessons Learned and Remaining Challenges in Disaster Risk Reduction; Fekete, A., Garschagen, M., Norf, C., Stephan, C., Eds.; TH Köln: Köln, Germany, 2017; Volume 2, pp. 87-91.

43. DKKV. Flutkatastrophe 7/2021. Aktuelle Forschungsaktivitäten. 2021. Available online: https://www.dkkv.org/de/ navigationsmenue/flutkatastrophe-07/2021/aktuelle-forschungsaktivitaeten (accessed on 20 October 2021).

44. Hudson, P.; Thieken, A.H.; Bubeck, P. The challenges of longitudinal surveys in the flood risk domain. J. Risk Res. 2020, 23, 642-663. [CrossRef]

45. Rufat, S.; Fekete, A.; Armaş, I.; Hartmann, T.; Kuhlicke, C.; Prior, T.; Thaler, T.; Wisner, B. Swimming alone? Why linking flood risk perception and behavior requires more than "it's the individual, stupid". WIREs Water 2020, 7, e1462. [CrossRef]

46. Tagesschau. Ermittlungen gegen Landrat von Ahrweiler. 2021. Available online: https://www.tagesschau.de/inland/ahrweiler115.html (accessed on 4 September 2021).

47. Nimrod, G. The benefits of and constraints to participation in seniors' online communities. Leis. Stud. 2014, 33, 247-266. [CrossRef]

48. Evans, J.R.; Mathur, A. The value of online surveys. Internet Res. 2005, 15, 195-219. [CrossRef]

49. Kaczmirek, L. Human-Survey Interaction: Usability and Nonresponse in Online Surveys; Universität Mannheim: Mannheim, Germany, 2008.

50. Fontainha, T.C.; Leiras, A.; Bandeira, R.A.d.M.; Scavarda, L.F. Stakeholder satisfaction in complex relationships during the disaster response: A structured review and a case study perspective. Prod. Plan. Control 2020, 1-22. Available online: https: / / www.tandfonline.com/doi/abs/10.1080/09537287.2020.1834127 (accessed on 4 September 2021). [CrossRef]

51. Kocaman, S.; Anbaroglu, B.; Gokceoglu, C.; Altan, O. A review on citizen science (CitSci) applications for disaster management. In Proceedings of the Gi4DM 2018: GeoInformation for Disaster Management, Istanbul, Turkey, 18-21 March 2018.

52. Raphael, B. When Disaster Strikes. A Handbook for the Caring Professions; Century Hutchinson: London, UK, 1986.

53. Mileti, D.S.; Drabek, T.E.; Haas, J.E. Human Systems in Extreme Environments: A Sociological Perspective; Institute of Behavioral Science, University of Colorado: Boulder, CO, USA, 1975.

54. Slovic, P. Perception of Risk. Science 1987, 236, 280-285. [CrossRef] [PubMed]

55. Fekete, A. Flood survey 2021 Questions. Year. Available online: https:/ / riskncrisis.wordpress.com/data/ (accessed on 21 October 2021).

56. Sefrin, P.; Händlmeyer, A.; Stadler, T.; Kast, W. Erfahrungen zur Gewalt gegen Rettungskräfte-aus der Sicht des DRK. Der Notarzt 2021, 37, S1-S19. [CrossRef]

57. BR. Diebe, Gaffer, Querdenker: Viel Ärger in den Flutgebieten. 2021. Available online: https://www.br.de/nachrichten/ deutschland-welt/regierung-verurteilt-hochwasser-falschmeldungen-niedertraechtig,SeSk6XV (accessed on 4 September 2021).

58. Die Zeit. Bilder der Zerstörung und der Solidarität. 2021. Available online: https://www.zeit.de/wissen/umwelt/2021-07/ hochwasser-deutschland-fotos-ueberschwemmungen-sonntag (accessed on 4 September 2021).

59. Grünewald, U. Vom Hochwasser- “Schutzversprechen” zum Hochwasser-“Risikomanagement”. In Hochwassermanagement; Jüpner, R., Ed.; Shaker: Aachen, Germany, 2005; pp. 5-22.

60. Fekete, A.; Hartmann, T.; Jüpner, R. Resilience: On-going wave or subsiding trend in flood risk research and practice? Wiley Interdiscip. Rev. Water 2020, 7, e1397. [CrossRef]

61. Shaw, R. Thirty years of science, technology, and academia in disaster risk reduction and emerging responsibilities. Int. J. Disaster Risk Sci. 2020, 11, 414-425. [CrossRef]

62. Baumert, N. Advancing Risk and Vulnerability Assessment for Decision-Making and Research: Case Study from the German-Indonesian Tsunami Early Warning System (GITEWS) Project; Niedersächsische Staats-und Universitätsbibliothek Göttingen: Göttingen, Germany, 2016.

63. Münch, U.; Rudloff, A.; Lauterjung, J. Postface “The GITEWS Project-results, summary and outlook". Nat. Hazards Earth Syst. Sci. 2011, 11, 765. [CrossRef]

64. Schlurmann, T.; Siebert, M. The Capacity Building programmes of GITEWS-visions, goals, lessons learned, and re-iterated needs and demands. Nat. Hazards Earth Syst. Sci. 2011, 11, 293-300. [CrossRef]

65. Zeit, D. Shuttle Hat 40.000 Private Helfer in Ahr-Flutgebiet Gebracht. 2021. Available online: https://www.zeit.de/news/2021-0 8/24/shuttle-hat-40000-private-helfer-in-ahr-flutgebiet-gebracht (accessed on 20 October 2021). 
66. Fahey, C.; Walker, J.; Sleigh, A. Training can be a recruitment and retention tool for emergency service volunteers. Aust. J. Emerg. Manag. 2002, 17, 3-7.

67. Rice, S.; Fallon, B. Retention of volunteers in the emergency services: Exploring interpersonal and group cohesion factors. Aust. J. Emerg. Manag. 2011, 26, 18-23.

68. Cowlishaw, S.; Evans, L.; McLennan, J. Work-family conflict and crossover in volunteer emergency service workers. Work Stress 2010, 24, 342-358. [CrossRef]

69. Zettl, V.; Ludwig, T.; Kotthaus, C.; Skudelny, S. Embedding Unaffiliated Volunteers in Crisis Management Systems: Deploying and Supporting the Concept of Intermediary Organizations. In Proceedings of the 14th International Conference on Information Systems for Crisis Response and Management, ISCRAM, Albi, France, 21-24 May 2017.

70. Prati, G.; Pietrantoni, L.; Saccinto, E.; Kehl, D.; Knuth, D.; Schmidt, S. Risk perception of different emergencies in a sample of European firefighters. Work 2013, 45, 87-96. [CrossRef] [PubMed]

71. Bierhoff, H.-W.; Burkart, T.; Wörsdörfer, C. Einstellungen und motive ehrenamtlicher Helfer. Gruppendynamik 1995, 26, 373-386.

72. Van der Auwera, M.; Debacker, M.; Hubloue, I. Monitoring the mental well-being of caregivers during the Haiti-earthquake. PLoS Curr. 2012, 4, e4fc33066f1947. [CrossRef]

73. Shipley, F.; Gow, K.M. State Emergency Service (SES) volunteer members: An investigation into coping abilities and adjustment strategies following emergency activations. Australas. J. Disaster Trauma Stud. 2006. Available online: https://psycnet.apa.org/ record/2006-10442-004 (accessed on 4 September 2021).

74. Karutz, H.; Overhagen, M.; Stum, J. Psychische Belastungen im Wachalltag von Rettungsdienstmitarbeitern und Feuerwehrleuten. Prävention und Gesundheitsförderung 2013, 8, 204-211. [CrossRef]

75. Hofinger, G.; Zinke, R.; Künzer, L. Human factors in evacuation simulation, planning, and guidance. Transp. Res. Rec. 2014, 2, 603-611. [CrossRef]

76. Oravec, G.J.; Artino, A.R., Jr.; Hickey, P.W. Active-duty physicians' perceptions and satisfaction with humanitarian assistance and disaster relief missions: Implications for the field. PLOS ONE 2013, 8, e57814. [CrossRef] [PubMed] 